\title{
Padrões de votação no tempo e no espaço: classificando as eleições presidenciais brasileiras
}

\author{
Maria do Socorro Braga ${ }^{1}$ (iD) \\ Aleksei Zolnerkevic ${ }^{2}$ (D)
}

\begin{abstract}
Em 2018, o Brasil realizou seu oitavo pleito presidencial pós-redemocratização, acumulando evidências empíricas cruciais para a análise das características dos processos eleitorais que podem ser responsáveis por mudanças substanciais na distribuição do poder entre os partidos políticos. A partir de base conceitual alicerçada em literatura internacional sobre eleições críticas, este artigo visa criar uma classificação para as eleições brasileiras. Como subsídio principal para essa classificação, é analisado simultaneamente, no tempo e no espaço, por meio da análise fatorial, o desempenho eleitoral dos primeiros colocados nas eleições presidenciais desde 1989 até 2018 em primeiro turno na escala das microrregiões brasileiras, buscando identificar as regiões de apoio duradouro e os períodos de estabilidade e mudança nos padrões de votação. Como resultado, as eleições presidenciais são classificadas em três tipos: mantidas, desviantes e convertidas (críticas).

Palavras-chave: eleições presidenciais; eleições críticas; realinhamento; comportamento eleitoral; Brasil
\end{abstract}

\section{Introdução ${ }^{3}$}

A eleição presidencial de 2018, que elegeu o candidato Jair Messias Bolsonaro, do Partido Social Liberal (PSL), isoladamente representou a ascensão de um candidato de extrema-direita ${ }^{4}$ (Löwy, 2015), com todas as suas consequências. Entretanto, analisando-a de uma forma sistemática e comparando-a com todas as outras eleições

\footnotetext{
1 Universidade Federal de São Carlos, Departamento de Ciências Sociais. São Carlos (SP), Brasil. E-mail: <msbraga@ufscar.br>.

2 Universidade de São Paulo, Departamento de Geografia. São Paulo (SP), Brasil.

E-mail: <alekseizolner@gmail.com>.

3 Este artigo está inserido no âmbito do projeto de pesquisa "Avaliando a qualidade da democracia em países da América Latina (II)", apoiado pela bolsa de produtividade em pesquisa do CNPq. Agradecemos aos pareceristas da revista Opinião Pública pelos valiosos comentários e sugestões.

4 Löwy (2015), ao comparar o conservadorismo no Brasil com os movimentos de extrema-direita na Europa, mais especificamente na França, aponta como semelhanças o culto à violência policial e a intolerância com as minorias sexuais. Ele vê, como uma particularidade do Brasil, o apelo aos militares (o chamado a uma intervenção militar, o saudosismo da ditadura militar etc.).
} 
presidenciais desde a redemocratização, ela representou também uma mudança na balança do poder político partidário com o partido até então hegemônico, o Partido dos Trabalhadores (PT), não elegendo o presidente após quatro mandatos consecutivos, apesar de continuar com a maior bancada parlamentar no Congresso Nacional.

O estudo das principais características presentes nos processos eleitorais, responsáveis por mudanças substanciais na distribuição do poder entre os partidos políticos, tem longa tradição na ciência política europeia e estadunidense. Mas, de acordo com Blondel (1981), a importância ampliou-se consideravelmente após os eventos que levaram à Segunda Guerra Mundial. Já na América Latina, onde a maioria dos países apresenta períodos efêmeros de experiências de competição partidária, interrompidas normalmente por intervenções militares, como é o caso brasileiro, esse campo de estudo somente mais recentemente começa a ter maior relevância. Contudo, embora o Brasil já tenha vivenciado oito pleitos presidenciais em 32 anos de experiência de eleições diretas para o principal cargo de sua democracia presidencialista, análises mais robustas ainda não foram realizadas.

Em contrapartida, diversos estudos na literatura estadunidense, desde os anos 1950, vêm buscando desenvolver uma forma de classificar as eleições presidenciais a partir da identificação de padrões de estabilidade e mudança nos resultados eleitorais (Key, 1955; Pomper, 1967; Archer e Taylor, 1981; Knuckey, 1999), nas preferências eleitorais no âmbito individual (Campbell, 1966) ou ainda em relação às agendas políticas adotadas (Schattschneider, 1975). O objetivo deste artigo é justamente classificar a série de eleições presidenciais brasileiras pós-redemocratização (de 1989 a 2018) a partir dessa base conceitual internacional, analisando simultaneamente no tempo e no espaço o desempenho eleitoral dos principais contendores, identificando períodos de estabilidade e mudança nos padrões de votação.

Para atingir o objetivo proposto, este artigo está organizado da seguinte maneira: Após esta Introdução, na seção "Considerações teóricas sobre tipos de eleições e suas consequências políticas", delimitamos, com apoio nas contribuições teóricas existentes, os principais elementos conceituais e a utilidade das categorias de tipos de eleições para a construção de uma classificação. Em seguida, em "Hipótese e metodologia: análise fatorial do modelo $\mathrm{S}$ e $\mathrm{T}^{\prime \prime}$, apresentamos a hipótese a ser verificada e a metodologia que irá operacionalizá-la. Em "Resultados empíricos" e "Classificando as eleições presidenciais", descrevemos e analisamos os resultados aferidos. Finalmente, em "Conclusões" destacamos os principais achados e reflexões deste artigo. 


\section{Considerações teóricas sobre tipos de eleições e suas consequências políticas}

\section{Eleições críticas e a teoria do realinhamento}

O estudo seminal de Key (1955) introduziu o conceito de "eleição crítica". Ao comparar os resultados eleitorais de uma série de eleições consecutivas em agregados geográficos (estados, municípios etc.), observou-se que em eleições específicas havia uma forte modificação nos padrões de votação em relação às anteriores, indicando uma "brusca alteração da clivagem preexistente dentro do eleitorado5". Esse tipo de eleição crítica caracterizar-se-ia por um realinhamento nos apoios eleitorais e persistiria por várias eleições subsequentes. Mais tarde, ponderou-se que esse realinhamento aconteceria de uma forma gradual em um processo de realinhamento denominado "secular" (Key, 1959).

No entanto, não há um consenso na literatura sobre se uma eleição crítica necessariamente geraria um realinhamento (Mayhew, 2002). Pomper (1967), em sua classificação sobre as eleições presidenciais, como veremos mais à frente, considera que a condição para uma eleição ser classificada como de realinhamento é a derrota do partido majoritário conjuntamente com uma mudança significativa nos padrões de votação que permanece nas eleições subsequentes. Já outros autores consideram que as condições para uma eleição de realinhamento não se restringiriam apenas à questão eleitoral e à da alternância de poder (Schattschneider, 1975; Sundquist, 1983): o realinhamento seria um fenômeno político raro que ocorreria em momentos de crise, quando a substituição do controle partidário e do governo no poder é seguida de mudanças concretas nas prioridades e agendas políticas para enfrentar as novas demandas surgidas em torno daquela eleição crítica. A consequência dessas ações efetivas, caso bem-sucedidas, seria a reorganização gradual da distribuição das lealdades do eleitorado em torno de uma nova e dominante clivagem que polarizaria o eleitorado durante vários ciclos eleitorais. Nesse sentido, o realinhamento eleitoral não ocorreria durante a eleição crítica, mas após sua realização, em um processo gradual.

A eleição crítica que precede um realinhamento seria caracterizada, de um lado, por uma forte preocupação do eleitorado sobre os assuntos de interesse que pautam aquela eleição, e, de outro lado, por um maior antagonismo nas propostas dos principais partidos políticos sobre esses temas centrais da eleição. Nos Estados Unidos, até os anos 1960, acreditava-se que o fenômeno do realinhamento ocorreria a cada 30 anos (Burnham6 ${ }^{6}$ 1967, apud Mayhew, 2002, p. 17) em consequência de uma crise ou de um

\footnotetext{
5 "(...) sharp alteration of the pre-existing cleavage within the electorate" (Key, 1955, p. 4).

${ }^{6}$ Burnham, W. D. Party systems and the political process. In: Chambers, W. N.; Burnham, W. (eds.). The American party systems: stages of political development. New York: Oxford University Press New York, cap. 10, 1967.
} 
importante assunto de interesse (Sundquist, 1983): escravidão (década de 1850), desigualdade na distribuição da renda e da riqueza entre regiões e classes (década de 1890) e a grande depressão (década de 1930).

Haveria também maior polarização ideológica e carga emocional durante o período de campanha eleitoral, assim como maior mobilização e participação do eleitorado. O trauma social e o peso emocional causados por esse processo, principalmente após a concretização da agenda política proposta pelo partido vencedor, faria com que, ao longo do tempo, o eleitorado absorvesse na sua identidade pessoal o apego ao seu partido de preferência e a hostilidade ao adversário. Desse modo, por uma geração, ocorreria um congelamento do comportamento eleitoral. Por fim, o "descongelamento" só ocorreria gradualmente com o aparecimento de novos eleitores não influenciados pela identificação induzida por aquele realinhamento (Beck , 1974, apud Mayhew, 2002, p. 19).

$\mathrm{Na}$ conjuntura da Europa Ocidental, a partir da teoria das clivagens sociais de Lipset e Rokkan (1990), que considerava que o sistema de partidos refletia uma série de clivagens sociais (centro-periferia, Estado-igreja, rural-urbana e de classes) surgidas durante os processos de desenvolvimento, modernização e nacionalização dos Estadosnação (Caramani, 2004) e que faria com que o apoio aos partidos ao longo do tempo se mantivesse estável, vários estudos, durante as décadas de 1980 e 1990, buscaram demonstrar o "descongelamento" desses apoios duros aos partidos tradicionais (Pedersen 1979; Bartolini e Mair, 1990) a partir dos anos 1970. Esses últimos estudos subsidiaram teorias explicativas sobre esse processo de "descongelamento", como é o caso da teoria do desalinhamento de Dalton, Scott e Beck (1984), que, assim como a tese do realinhamento, considerava os novos assuntos de interesses não representados pelos partidos tradicionais - a questão ambiental (partidos verdes), por exemplo - como um dos principais motivos para a quebra da estabilidade nos padrões de votação.

O exemplo clássico de eleição crítica, seguida de um processo gradual de realinhamento, é o das duas primeiras eleições presidenciais de Franklin Roosevelt, do Partido Democrata, nos Estados Unidos. Após três mandatos consecutivos do Partido Republicano, Roosevelt, com a promessa de solucionar os problemas causados pela grande depressão de 1929, é eleito presidente em uma grande vitória, conquistando 42 estados e $57 \%$ dos votos populares. Durante seu primeiro mandato, Roosevelt implementou medidas efetivas para a realização do seu projeto de governo, fazendo uma série de reformas legislativas nos seus 100 primeiros dias de governo (política do New Deal). O sucesso de suas políticas fez com que, quatro anos depois, fosse reeleito numa votação ainda mais expressiva (conquista 46 estados e $60 \%$ dos votos). O Partido Democrata, em um efeito coattail, conquistou a maioria das cadeiras nas duas casas do congresso estadunidense, reorganizando definitivamente a lealdade partidária dos

\footnotetext{
7 Beck, P. A. A socialization theory of partisan realignments. In: Niemi, R. (ed.). The politics of future citizens. San Francisco: Jossey-Bass, 1974.
} 
eleitores na chamada "coalizão moderna de apoio ao Partido Democrata" (Shelley et al., 1996): classe trabalhadora, minorias raciais, imigrantes europeus e liberais. Assim, a clivagem seccional (norte-sul ou núcleo-periferia), que até então mobilizava o eleitorado estadunidense, foi substituída por uma clivagem nacional de classe, permanecendo importante até os dias de hoje.

Voto normal: eleições mantidas e desviantes

Com base no estudo de Key (1955) sobre as eleições críticas, pesquisadores da Universidade de Michigan desenvolveram o conceito de "voto normal" (Converse, 1966) a partir de seus estudos sobre pesquisas de opinião.

Segundo a teoria do funil de causalidade (Campbell et al., 1960), existiria um conjunto de causas que determinariam a decisão eleitoral do indivíduo no dia do pleito, causas mais antigas e duradouras relacionadas à distribuição estável das identidades partidárias entre grupos sociais e causas mais recentes relacionadas a acontecimentos do período eleitoral atual. Enquanto a tendência do eleitor de se decidir a partir de estímulos acumulativos passados que determinaram seu voto nas eleições anteriores produziria o voto normal, os estímulos recentes, relacionados a acontecimentos próximos à eleição atual, produziriam uma variação desse voto normal, que poderia ser permanente ou não. Dessa forma, o conceito de voto normal teria dois componentes: o alinhamento, ou divisão, eleitoral "normal" esperado para certo grupo social com base no seu comportamento eleitoral retrospectivo e o desvio dessa normalidade em função das causas de curto prazo associadas a uma eleição específica.

Campbell (1966), ao assumir a existência de um alinhamento do eleitorado fundamentado no conceito de voto normal, busca classificar as eleições presidenciais em três tipos: mantidas, desviantes e de realinhamento. Seu argumento é o de que a flutuação do voto normal em torno das causas de curto prazo de cada eleição específica pode oscilar entre o partido majoritário e o minoritário e, caso esteja associada também a uma alteração das identidades partidárias dos eleitores, pode causar mudanças significativas nos apoios eleitorais.

Nas eleições mantidas, os padrões de apoio da eleição anterior se mantêm e o partido majoritário ganha as eleições. Caso os acontecimentos de curto prazo não sejam relevantes, a votação irá se aproximar do voto normal e haverá também um baixo comparecimento às urnas. Se as causas de curto prazo forem fortes, o apoio eleitoral irá oscilar positivamente ou a favor do partido majoritário, recebendo uma votação maior do que a normal, ou a favor do minoritário, mas não o suficiente para este ganhar as eleições.

Nas eleições desviantes, quando as causas de curto prazo são fortes, os padrões de apoio eleitoral alteram-se suficientemente para que o partido minoritário ganhe as eleições. No entanto, com o passar do tempo, essas causas específicas que contribuíram 
para a flutuação do voto normal desaparecem e os apoios eleitorais retornam aos padrões esperados, o que, teoricamente, reflete mais a distribuição estável da identidade partidária no eleitorado. Campbell (1966) utiliza como exemplo de eleições desviantes as duas eleições presidenciais $(1952,1956)$ vencidas pelo candidato republicano Eisenhower. Na eleição de 1952, seu partido ganha tanto a presidência quanto as duas casas legislativas, com uma grande parcela de votos de democratas e independentes. Porém, tanto nas eleições legislativas de meio de mandato (1954) quanto na eleição de reeleição (1956), os democratas retomam o controle do Congresso, indicando que, apesar do apoio popular ao presidente, principalmente por ter sido herói de guerra nacional, após a eleição crítica de 1952, nem sua popularidade pessoal nem as ações práticas do seu governo foram capazes de alterar as linhas de divisão "normal" de apoio aos partidos formadas durante o New Deal.

Finalmente, nas eleições consideradas de realinhamento, como vimos anteriormente, os anseios populares relacionados às políticas em discussão na eleição são de tal forma intensos que as bases de apoio partidário que formavam o voto normal se alteram e um novo padrão de apoio é criado. Em contraposição às eleições de Eisenhower, o autor argumenta que, na história estadunidense, as eleições de realinhamento não foram caracterizadas por candidatos que vieram ao cargo com uma grande popularidade ou apelo pessoal8 (Lincoln, 1860; McKinley, 1896; Roosevelt, 1932), mas por grandes crises nacionais, que fizeram com que essas eleições tomassem um caráter ideológico, no sentido de discussão de ideias, reorientando as identidades partidárias básicas dos eleitores.

A classificação de Pomper (1967) e as eleições convertidas

Um quarto tipo de eleição é mencionado em Pomper (1967). A partir do estudo de Key (1955) sobre eleições críticas e dos conceitos de eleição mantida, desviante e de realinhamento de Campbell (1966) baseados no conceito de voto normal (Converse, 1966), Pomper (1967) criou uma classificação para as eleições presidenciais estadunidenses, analisando os resultados das eleições de 1832 a 1960.

O autor estuda os resultados eleitorais do partido democrata comparando, em uma análise estatística, a porcentagem de votos por estado de cada eleição com a anterior através do índice de correlação $\mathrm{R}$ de Pearson. Em uma segunda etapa, é comparada a porcentagem de votos por estado em cada ano com a média da porcentagem de votos das quatro eleições consecutivas anteriores com o objetivo de compensar os fatores de curto prazo de cada eleição de acordo com a teoria do voto normal (Converse, 1966). Por fim, a partir dos valores de correlação para cada eleição, é

\footnotetext{
${ }^{8}$ Como é o caso, na eleição presidencial brasileira de 2018 , do bolsonarismo.
} 
gerada uma tabela de matriz em que, de acordo com o autor, são identificadas as "eras", períodos de estabilidade nos padrões de votação para o Partido Democrata.

A partir dessa análise, Pomper classifica as eleições em quatro tipos (Quadro 1):

Quadro 1

Classificação das eleições presidenciais de acordo com o esquema de Pomper (1967)

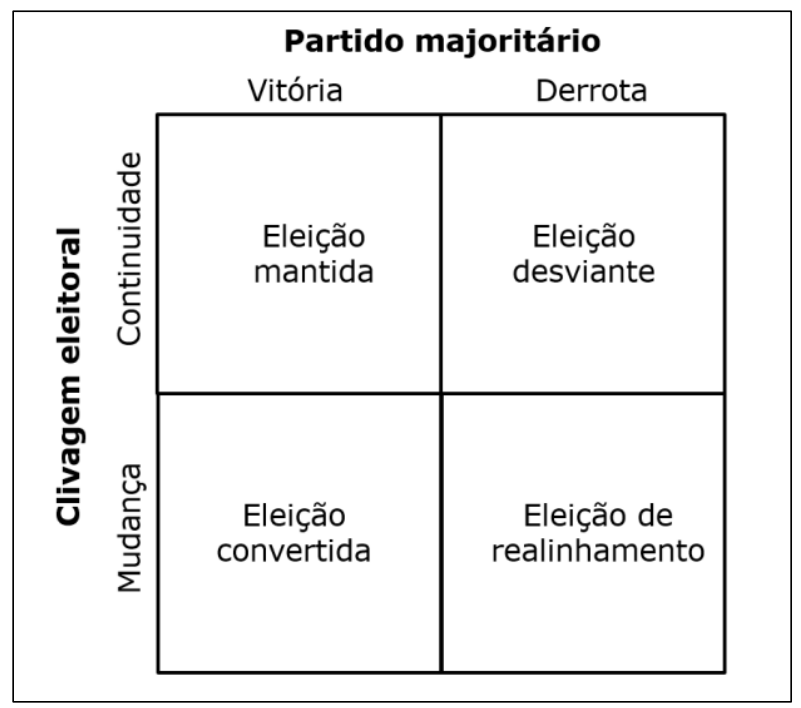

Fonte: Pomper (1967), adaptado pelos autores.

1. Eleição mantida - O partido majoritário ganha as eleições e há uma alta correlação estatística entre a porcentagem de votos da eleição em questão com a anterior, significando que houve uma estabilidade dos padrões de voto.

2. Eleição desviante - O partido majoritário perde as eleições, mas a correlação estatística entre a porcentagem de votos da eleição em questão e a anterior continua sendo alta, indicando que, apesar da derrota do partido majoritário, as linhas de apoio eleitoral mantêm-se relativamente estáveis, ocorrendo, no entanto, uma flutuação acentuada dos apoios eleitorais baseada no voto normal a favor do partido minoritário.

3. Eleição de realinhamento - O partido majoritário perde as eleições e a correlação estatística entre a porcentagem de votos da eleição atual e a da anterior é baixa, significando que houve uma mudança nos padrões de votação. Ou seja, o partido minoritário ganha as eleições sobre uma nova base de apoio eleitoral.

4. Eleição convertida - O partido majoritário ganha as eleições, mas a correlação estatística entre essa eleição e a anterior é baixa, ou seja, houve 
uma continuidade partidária no poder, mas as bases de apoio eleitoral se modificaram.

Teoricamente, o conceito de eleição convertida se enquadra bem no processo que a literatura denominou de "realinhamento secular" (Key, 1959), ou seja, quando ocorre uma mudança gradual nos padrões de apoio eleitoral. Em uma primeira eleição classificada como desviante, ocorreria uma troca de partido no poder, mas sem uma alteração significativa dos padrões de votação. Como descrito nos estudos sobre realinhamento (Schattschneider, 1975; Sundquist, 1983; Mayhew, 2002), esse novo partido no poder, ao adotar medidas efetivas para enfrentar o assunto de interesse pelo qual foi eleito, tem sua administração aprovada e é reeleito. Nessa eleição subsequente, o mesmo partido ganha as eleições, mas agora com uma nova base de apoio eleitoral "moldada" pelas políticas realizadas no primeiro mandato. Nesse caso, essa segunda eleição seria classificada como convertida, ou seja, o novo partido majoritário ganha as eleições, mas há uma mudança nos padrões de votação. Por fim, essas duas eleições juntas, uma classificada como desviante e a outra como convertida, poderiam então ser entendidas como parte de um processo de realinhamento secular (Key, 1959) ou gradual.

Porém, o próprio estudo de Pomper (1967) aponta problemas na operacionalização desse conceito de eleição convertida. Na sua análise sobre as eleições presidenciais estadunidenses, a eleição presidencial de 1928, que antecedeu o New Deal e elegeu o republicano Herbert Hoovert, na comparação dos resultados eleitorais em porcentagem para o Partido Democrata por estado, apresentava um padrão de votação mais parecido com a eleição subsequente de 1932 do que com a anterior de 1924, podendo, assim, ser teoricamente classificada como uma eleição convertida e não mantida. Em vez de essa eleição convertida significar uma alteração dos padrões de votação como consequência das políticas promovidas pelo governo no poder, podemos pensar que essa mudança significa apenas o esgotamento da clivagem eleitoral que mobilizava os eleitores anteriormente desde a década de 1890. O estudo revela que o candidato democrata Al Smith havia perdido 10 pontos percentuais em estados sulistas (até então reduto democrata) na eleição de 1928, enquanto havia ganhado em votos em outros estados com caraterísticas relacionadas ao voto republicano (urbano católico e rural progressista), indicando, portanto, que já havia um movimento de mudança dentro do eleitorado quatro anos antes da primeira vitória de Roosevelt na eleição de 1932, classificada como de realinhamento.

O estudo de Knuckey (1999), que busca seguir o trabalho de Pomper (1967), agora analisando as eleições presidenciais estadunidenses de 1932 a 1996, adota, em vez da classificação de Pomper (1967) com quatro tipos, uma versão alternativa com apenas três, substituindo os termos "eleição convertida" e "eleição de realinhamento" pelo termo "eleições críticas". Segundo ele, o interesse principal é identificar as 
mudanças eleitorais que resultam em novos alinhamentos estáveis, e não verificar se estes resultam na ascendência de um novo partido majoritário ao poder (Knuckey, 1999, p. 643), que é a diferença essencial entre eleição convertida e de realinhamento.

Volatilidade e a teoria do desalinhamento

Embora o termo "desalinhamento" não seja utilizado para classificar uma eleição, o processo ao qual ele se refere afeta diretamente a estabilidade dos padrões de votação ao longo do tempo. A teoria do desalinhamento (Dalton, Scott e Beck, 1984; Dalton, McAllister e Wattenberg, 2003), ao observar um aumento nos índices de volatilidade eleitoral nos países da Europa Ocidental e nos Estados Unidos, argumenta que essa instabilidade eleitoral seria causada pela diminuição do papel dos partidos políticos no processo de socialização e mobilização política das pessoas. Com a diminuição da influência mobilizadora dos partidos políticos, os níveis de identificação, filiação partidária e participação eleitoral também teriam diminuído, resultando em maior imprevisibilidade dos resultados eleitorais ao longo dos anos (volatilidade eleitoral).

Essa diminuição do papel dos partidos políticos seria causada, principalmente, por uma mudança na estrutura das sociedades, que acabaria tornando as linhas de divisão entre os estratos sociais menos evidentes, alterando consequentemente os padrões de identidade coletiva dos eleitores. Com a modernização da economia e a adoção do modo flexível de produção, houve redução do número de trabalhadores industriais e aumento da fragmentação dos postos de trabalho com diferentes níveis de exclusão social, tornando as demandas dos trabalhadores mais setorizadas e individuais e mais difíceis de serem representadas pelas organizações coletivas de classe tradicionais, como os sindicatos (Dalton, McAllister e Wattenberg, 2000; Gallagher, Laver e Mair, 2011).

O aumento do nível educacional dos eleitores, em conjunto com um maior acesso às mídias de massa, como a televisão, teria também contribuído para que eles ficassem cada vez mais independentes dos partidos, tornando as decisões eleitorais mais individualizadas e levando as pessoas a prescindirem de atalhos cognitivos de referências sociais e das legendas partidárias para a tomada de suas decisões eleitorais.

Por fim, para se adequar a essa nova realidade, os partidos buscaram também se modernizar e ampliar suas agendas políticas para além das suas linhas sociais de sustentação básica. Os partidos de centro-esquerda, por exemplo, vendo a sua base social de apoio se fragmentar, procuraram ampliar a sua agenda em um movimento catch all para o centro com o objetivo de atrair setores da classe média. No entanto, esse movimento, no longo prazo, provocou pelo menos duas consequências: 1. reduziu, no eleitorado, a percepção das diferenças ideológicas entre os partidos tradicionais, os quais falharam em restaurar os níveis de prosperidade social anteriores às crises econômicas mundiais, como a de 2008; e 2. esse fracasso levou uma porção significativa dos eleitores a flertar com partidos e candidatos populistas dos dois extremos do espectro 
ideológico, como Bernie Sanders e Donald Trump, nos Estados Unidos, na eleição presidencial de 2016 (Inglehart e Norris, 2016).

Nos países da América Latina, o afastamento dos eleitores em relação aos partidos estabelecidos, além de estar relacionado com o desempenho econômico dos governos, deve-se também aos altos níveis de corrupção entre os membros dessas organizações (Carreras, Morgenstern e Su, 2013). Os candidatos "anti-establishment" ou "outsiders", prometendo combater a corrupção, aproveitam-se justamente desse descontentamento para obter apoio junto ao eleitorado, como é o caso do candidato Bolsonaro na eleição presidencial de 2018.

$\mathrm{Na}$ prática, o processo de desalinhamento resulta em uma diminuição da importância dos estímulos de longo prazo sobre o voto dos eleitores, como as identidades partidárias, que, como vimos, são fatores estabilizadores dos apoios eleitorais. Assim, os eleitores acabam sendo mais influenciados por estímulos de curto prazo relacionados aos acontecimentos do período eleitoral, fazendo com que os resultados das eleições se tornem cada vez mais imprevisíveis e voláteis.

Esse processo deixa os eleitores mais vulneráveis e receptivos ao surgimento de novos partidos e candidatos, teoricamente menos enraizados na sociedade (como os de extrema-direita), que, por sua vez, buscam uma conexão direta com os eleitores por meio, por exemplo, do personalismo. Esses partidos e candidatos, portanto, veem nesse processo de crise dos partidos tradicionais uma oportunidade para obter apoio dessa parcela cada vez maior do eleitorado "desalinhado".

Por fim, uma discussão trazida por Carreras, Morgenstern e Su (2013) é que, na maioria dos países da África, do Leste Europeu e da América Latina, não seria adequado utilizar as terminologias "realinhamento" ou "desalinhamento" eleitoral ao tratar dos apoios eleitorais. O argumento seria que os sistemas partidários nesses países nunca foram suficientemente estáveis ao longo do tempo, nem tiveram partidos suficientemente programáticos para que se desenvolvessem alinhamentos partidários duradouros com o eleitorado. Haveria nesses países o que os autores denominam de "alinhamentos parciais", em que uma porção substancial do eleitorado vai se tornando alinhada a um ou mais partidos políticos ao longo do tempo, enquanto a porção restante se mantém não alinhada. Nesse sentido, seria mais frequente o processo de "desalinhamento parcial", quando algum desses partidos, que em determinado momento conseguiu criar vínculos junto ao eleitorado, se desintegrou ou perdeu apoio devido, por exemplo, a denúncias de corrupção, enquanto os demais mantiveram os vínculos. O exemplo paradigmático de um "desalinhamento parcial" seria o da Argentina, em que um dos grandes partidos, União Cívica Radical, desaparece, enquanto o outro, o Partido Justicialista, mantém a lealdade dos seus apoiadores. 


\section{Hipótese e metodologia: análise fatorial do modelo S e T}

A hipótese deste artigo é de que é possível classificar as eleições presidenciais brasileiras de 1989 a 2018 nos quatro tipos conceituados na seção anterior (eleições mantidas, desviantes, de realinhamento ou convertidas), considerando as seguintes variáveis:

1. Identificação de períodos de estabilidade e mudança nos padrões espaciais de votação, utilizando dados agregados sobre os resultados eleitorais, mais especificamente, os resultados em porcentagem na escala de microrregião ${ }^{9}$ observados por meio de análise fatorial.

2. Informação sobre qual era o partido majoritário no momento da eleição. No caso estadunidense, a decisão sobre qual é o partido majoritário, mais do que simplesmente status de partido incumbente ou desafiante, tem relação com a configuração das forças no Legislativo federal. É o caso da reeleição do presidente republicano Eisenhower (1956), quando seu partido perdeu a maioria no Congresso para os democratas dois anos antes. No caso do Brasil, adotamos a incumbência como fator principal para essa escolha devido à elevada fragmentação do Legislativo federal e à quantidade de candidatos a presidente (principalmente nas eleições de 1989 e 2018).

3. Informação sobre continuidade ou mudança nas agendas políticas dos governos eleitos. Como vimos, os estudos sobre a teoria do realinhamento argumentam que a mudança da agenda política de um governo e a aprovação ou não desta pelo eleitorado podem ser importantes para diferenciar uma eleição desviante de um processo de realinhamento.

Para checarmos essa hipótese, utilizamos como parâmetro para a análise fatorial o estudo pioneiro na geografia eleitoral estadunidense de Archer e Taylor (1981), que introduziu o uso dessa técnica estatística como subsídio para analisar as eleições presidenciais. Assim como Pomper (1967), Archer e Taylor (1981) analisam o desempenho eleitoral do Partido Democrata nas eleições presidenciais na escala dos estados estadunidenses buscando identificar padrões de estabilidade e de mudança, tanto no tempo quanto no espaço, através de dois modelos de análise fatorial T e S.

No modelo T (time), correlacionam-se, simultaneamente, os resultados eleitorais em porcentagem de uma série de eleições consecutivas agregadas por unidades geográficas (estados, microrregiões, municípios etc.) agrupando eleições com padrões de votação semelhantes em um mesmo fator. Interpretando os resultados a partir dos

\footnotetext{
9 Adotamos essa escala por dois motivos: primeiro, porque o número de municípios variou significativamente de 1989 a 2018 (de 4.491 municípios para 5.570). Ao adotarmos a escala das microrregiões, o N é fixado em 558 unidades; segundo, a escala de microrregiões é a mais adequada para se representar graficamente e permitir uma melhor análise visual do conjunto do país (Jacob et al., 2009).
} 
estudos sobre eleições críticas na América do Norte, Archer e Taylor (1981) consideram que eleições consecutivas com altas cargas fatoriais agrupadas em um mesmo fator indicam a existência de um período ou "era" de estabilidade nos padrões de votação, enquanto eleições que apresentam cargas fatoriais mais baixas seriam classificadas como desviantes. Já a formação de dois ou mais fatores, em que, em um deles, uma série de eleições consecutivas apresenta altas cargas fatoriais e, em um segundo fator, o mesmo aconteça com outra série de eleições consecutivas, pode significar a existência de uma eleição crítica de realinhamento entre essas duas séries estáveis (Johnston et al., 2017).

Já no modelo S (space), em vez de eleições consecutivas, correlacionam-se unidades geográficas (estados, microrregiões, municípios etc.) com padrões de votação semelhantes ao longo de um período específico no tempo ${ }^{10}$. A ideia é a de o modelo $\mathrm{S}$ ser aplicado para cada agrupamento de eleições consecutivas encontrado (no modelo T), que representaria teoricamente um período de estabilidade nos padrões de votação. Dessa forma, buscar-se-ia identificar, através do modelo $S$, as regiões de apoio eleitoral duradouro para os partidos durante esses períodos de estabilidade encontrados. 0 estudo de Figueiredo et al. (2002) sobre a distribuição de votos dos partidos políticos nas eleições na cidade de São Paulo de 1994 até 2000 é um dos poucos exemplos da utilização desse modelo $S$ de análise fatorial no Brasil ${ }^{11}$.

De uma forma resumida, enquanto no modelo $T$ busca-se agrupar eleições consecutivas com padrões de votação semelhantes, no modelo $S$ os dados são transpostos e busca-se agrupar unidades geográficas com padrões de votação semelhantes em um período de tempo específico.

Em ambos os modelos ( $T$ e $S$ ), utiliza-se o método de redução de dados, denominado análise de componentes principais (ACP), em que toda a variância dos dados é utilizada, tanto a comum quanto a compartilhada. Em relação ao tipo de rotação dos fatores, que torna o resultado empírico encontrado mais facilmente interpretável (Figueiredo Filho e Silva Junior, 2010), no modelo T é utilizado o método de rotação fatorial "oblíqua", que permite que os fatores se correlacionem entre si, aumentando a probabilidade de a análise fornecer cargas fatoriais intermediárias que representariam eleições desviantes, enquanto no modelo S é utilizado o método "ortogonal", que assume que os fatores extraídos são independentes entre si (não se correlacionam), fornecendo muitas cargas fatoriais altas e baixas e poucas intermediárias para cada variável. Esse método seria a melhor opção quando se quer obter regiões geográficas uniformes (Archer e Taylor, 1981).

Nos estudos sobre as eleições presidenciais estadunidenses (Pomper, 1967; Knuckey, 1999), como vimos, foram utilizados na análise apenas os resultados eleitorais,

\footnotetext{
10 Segundo Clark Archer: "The S-mode analysis can be thought of as summarizing correlations between districts over elections" (informação pessoal - mensagem recebida por <alekseizolner@gmail.com> em 23 de setembro de 2016).

11 Mesmo que os autores não utilizem essa denominação no trabalho.
} 
em porcentagem, agregados por estado, de um dos dois grandes partidos políticos, o Partido Democrata. Como o sistema partidário estadunidense é virtualmente bipartidário, entende-se que, ao analisar o resultado eleitoral de um, está se "espelhando" o do outro. Vale ressaltar que estudos sobre realinhamento (Mayhew, 2002) argumentam que terceiros partidos ${ }^{12}$ na história estadunidense sempre estiveram relacionados com períodos de mudança na política daquele país e que a ascensão momentânea destes pode ser entendida como um indício do descontentamento e de uma mobilização dos eleitores fora do normal.

No caso deste artigo, decidiu-se por analisar os resultados eleitorais dos dois primeiros colocados em cada eleição presidencial de 1989 a 2018, usando como referência o desempenho do Partido dos Trabalhadores (PT), que esteve nessas posições durante todo esse período. Após a vitória do candidato Jair Bolsonaro (PSL), em 2018, que, assim como Collor (PRN), substituiu o candidato do PSDB nessa alternância das primeiras posições na eleição presidencial, estudos recentes sobre comportamento eleitoral e identidade partidária (Samuels e Zucco, 2014; Ribeiro, Carreirão e Borba, 2016; Samuels e Zucco, 2018) argumentam que o comportamento dos eleitores no Brasil, desde a redemocratização, estaria orbitando em torno do PT em uma dicotomia petismo e antipetismo, ou seja, as duas forças mobilizadoras do eleitorado durante as eleições presidenciais teriam sido o voto a favor ou contra o partido. Esse voto contrário ao PT, que aqui denominamos "forças antipetistas", teria sido representado pelo PRN, em 1989, pelo PSDB, entre 1994 e 2014 e, finalmente, pelo PSL, em 2018.

Com a análise fatorial do modelo $T$ aplicada, tanto para a porcentagem de votos do PT nas eleições presidenciais na escala das microrregiões quanto para as forças antipetistas, buscamos identificar os períodos de estabilidade e mudança nos padrões espaciais de votação ao longo do tempo para ambos os grupos, analisando-os conjuntamente como subsídio para nossa classificação das eleições presidenciais.

Para determinar a continuidade ou mudança nas agendas políticas dos governos eleitos, buscamos identificar certos momentos históricos de ruptura a partir da análise da literatura que trata desses períodos, como o impeachment do governo Collor, o Plano Real nos governos Itamar e FHC, a ênfase nas políticas sociais nos governos petistas, assim como o caráter reformista liberal dos governos Temer e Bolsonaro.

\section{Resultados empíricos}

Para checar a nossa hipótese, primeiramente, assim como nos estudos de Pomper (1967) e Knuckey (1999), geramos duas tabelas matrizes que mostram a comparação da porcentagem de votos em primeiro turno por microrregião de cada

\footnotetext{
12 Liberty Party e Free Soil Party na década de 1840; Greenback Party e Populist Party na década de 1890; e Progressive Party na década de 1920 (Mayhew, 2002); e o candidato independente Ross Perot na eleição presidencial de 1992.
} 
eleição com a anterior desde 1989 a 2018 através do índice de correlação R de Pearson tanto para os resultados do PT quanto para as forças antipetistas (Tabelas 1 e 2, respectivamente):

Tabela 1

Matriz de correlação dos resultados em porcentagem do PT na escala das microrregiões das eleições de 1989 a 2018

\begin{tabular}{|l|c|c|c|c|c|c|c|c|}
\hline & PT-89 & PT-94 & PT-98 & PT-02 & PT-06 & PT-10 & PT-14 & PT-18 \\
\hline PT-89 & 1 & & & & & & & \\
\hline PT-94 & 0,558 & 1 & & & & & & \\
\hline PT-98 & 0,223 & 0,760 & 1 & & & & & \\
\hline PT-02 & 0,344 & 0,589 & 0,585 & 1 & & & & \\
\hline PT-06 & 0,494 & 0,139 & $-0,047$ & $-0,132$ & 1 & & & \\
\hline PT-10 & 0,276 & 0,094 & $-0,03$ & $-0,178$ & 0,875 & 1 & & \\
\hline PT-14 & 0,234 & 0,044 & $-0,071$ & $-0,246$ & 0,842 & 0,928 & 1 & \\
\hline PT-18 & 0,357 & 0,121 & $-0,086$ & $-0,146$ & 0,805 & 0,861 & 0,886 & 1 \\
\hline
\end{tabular}

Fonte: Elaborada pelos autores com base em dados do TSE e do IBGE.

Nota: Cargas fatoriais altas e médias em destaque.

Tabela 2

Matriz de correlação dos resultados em porcentagem das forças antipetistas na escala das microrregiões das eleições de 1989 a 2018

\begin{tabular}{|l|c|c|c|c|c|c|c|c|}
\hline & PRN-89 & PSDB-94 & PSDB-98 & PSDB-02 & PSDB-06 & PSDB-10 & PSDB-14 & PSL-18 \\
\hline PRN-89 & 1 & & & & & & & \\
\hline PSDB-94 & 0,705 & 1 & & & & & & \\
\hline PSDB-98 & 0,498 & 0,584 & 1 & & & & & \\
\hline PSDB-02 & 0,138 & 0,166 & 0,567 & 1 & & & & \\
\hline PSDB-06 & $-0,193$ & $-0,199$ & 0,308 & 0,400 & 1 & & & \\
\hline PSDB-10 & $-0,097$ & $-0,102$ & 0,360 & 0,385 & 0,927 & 1 & & \\
\hline PSDB-14 & $-0,244$ & $-0,182$ & 0,262 & 0,289 & 0,906 & 0,876 & 1 & \\
\hline PSL-18 & $-0,246$ & $-0,230$ & 0,223 & 0,084 & 0,794 & 0,79 & 0,886 & 1 \\
\hline
\end{tabular}

Fonte: Elaborada pelos autores com base em dados do TSE e do IBGE.

Nota: Cargas fatoriais altas e médias em destaque.

Em seguida, aplicamos a análise fatorial do modelo $\mathrm{T}$ para os mesmos dados, utilizando o método de rotação do tipo "oblíqua" e o critério de Kaiser ${ }^{13}$ para definir a quantidade de fatores. Ambos os modelos resultam na extração de dois fatores, explicando $79 \%$ da variabilidade dos dados (Anexos 1 e 2 ).

13 Extrair apenas os fatores com valor de eigenvalue acima de 1 (Figueiredo Filho e Silva Junior, 2010). 
Examinando as duas matrizes e as cargas fatoriais extraídas de ambas as análises fatoriais (Tabelas 3 e 4), segundo a interpretação sugerida por Archer e Taylor (apud Johnston et al., 2017), os dados indicam a existência de dois períodos de estabilidade nos padrões de votação ao longo do tempo. Um período com a sequência de eleições consecutivas com altas cargas fatoriais que, na análise sobre os resultados do PT, vai de 1994 a 2002, e das forças antipetistas, que vai de 1989 a 1998; e um segundo período de estabilidade entre 2006 e 2018, coincidente para os dois grupos. Como cada uma dessas sequências de eleições consecutivas com altas cargas fatoriais encontra-se em fatores diferentes, entende-se que haveria uma eleição crítica entre elas, no caso a eleição de 2006, que, como veremos adiante, foi classificada como uma eleição "convertida".

Tabela 3

Cargas fatoriais extraídas da análise fatorial do modelo $\mathrm{T}$ para os resultados eleitorais do PT em primeiro turno nas eleições presidenciais de 1989 a 2018 na escala das microrregiões brasileiras

\begin{tabular}{|l|c|c|c|c|c|c|c|c|}
\hline Partidos & \multicolumn{7}{|c|}{ PT } \\
\hline Eleições & $\mathbf{1 9 8 9}$ & $\mathbf{1 9 9 4}$ & $\mathbf{1 9 9 8}$ & $\mathbf{2 0 0 2}$ & $\mathbf{2 0 0 6}$ & $\mathbf{2 0 1 0}$ & $\mathbf{2 0 1 4}$ & $\mathbf{2 0 1 8}$ \\
\hline Fator 1 & 0,438 & 0,137 & $-0,069$ & $-0,190$ & $\mathbf{0 , 9 4 0}$ & $\mathbf{0 , 9 5 2}$ & $\mathbf{0 , 9 4 9}$ & $\mathbf{0 , 9 3 3}$ \\
\hline Fator 2 & 0,612 & 0,920 & 0,835 & 0,804 & 0,090 & 0,007 & $-0,058$ & 0,029 \\
\hline
\end{tabular}

Fonte: Elaborada pelos autores com base em dados do TSE e do IBGE. Nota: Cargas fatoriais altas e médias em destaque.

\section{Tabela 4}

Cargas fatoriais extraídas da análise fatorial do modelo $\mathrm{T}$ para os resultados eleitorais das forças antipetistas em primeiro turno nas eleições presidenciais de 1989 a 2018 na escala das microrregiões brasileiras

\begin{tabular}{|l|c|c|c|c|c|c|c|c|}
\hline Partidos & PRN & PSDB & PSDB & PSDB & PSDB & PSDB & PSDB & PSL \\
\hline Eleições & $\mathbf{1 9 8 9}$ & $\mathbf{1 9 9 4}$ & $\mathbf{1 9 9 8}$ & $\mathbf{2 0 0 2}$ & $\mathbf{2 0 0 6}$ & $\mathbf{2 0 1 0}$ & $\mathbf{2 0 1 4}$ & $\mathbf{2 0 1 8}$ \\
\hline Fator 1 & $-0,229$ & $-0,200$ & 0,361 & 0,417 & 0,963 & 0,946 & 0,958 & 0,885 \\
\hline Fator 2 & 0,809 & 0,847 & 0,849 & 0,528 & 0,039 & 0,125 & $-0,021$ & $-0,105$ \\
\hline
\end{tabular}

Fonte: Elaborada pelos autores com base em dados do TSE e do IBGE.

Nota: Cargas fatoriais altas e médias em destaque.

Com a avaliação dessas duas sequências de eleições consecutivas, buscamos identificar as regiões com padrões de votação parecidos nesses períodos de estabilidade a partir da análise fatorial do modelo S. As eleições de 1989 e 2002 são deixadas de fora dessa análise por apresentarem, em uma das análises fatoriais do modelo $T$, cargas fatoriais intermediárias e que, segundo Archer e Taylor (apud Johnston et al., 2017), poderiam ser classificadas como desviantes. Na eleição de 1989, como a matriz de correlação mostra (Tabela 1), o padrão de votação do PT é semelhante ao do partido em 
1994 e 2006, enquanto o padrão de votação do PSDB no primeiro turno de 2002 se assemelha ao padrão de votação do partido na eleição de 1998 e 2006, ou seja, essas duas eleições (1989 e 2002) apresentam padrões semelhantes aos das eleições dos dois períodos de estabilidade identificados, 1994-1998 e 2006-2018.

A análise fatorial do modelo $S$ referente ao período 1994-1998, utilizando o método de rotação do tipo ortogonal Varimax, resulta na extração de três fatores "naturais" representando $100 \%$ da variabilidade dos dados (Figura 1 e Anexos 3 e 4). Observando a média da porcentagem de votos das microrregiões com cargas fatoriais maiores que 0,6 para cada fator (Tabela 5), os dados indicam que o fator 1 refere-se ao amplo agrupamento de microrregiões onde o PSDB, partido majoritário nesse período, foi bem votado; o fator 3, às regiões de apoio ao PT, microrregiões localizadas principalmente no Rio Grande do Sul, Santa Catarina e Rio de Janeiro; e o fator 2, às regiões intermediárias onde ocorre uma queda no apoio ao PSDB, possivelmente causada pela força de um terceiro candidato competitivo na eleição de 1998 (Ciro Gomes).

Figura 1

Representação gráfica das cargas fatoriais extraídas da análise fatorial do modelo $S$ referente aos resultados eleitorais dos dois primeiros colocados nas eleições presidenciais de 1994 e 1998 na escala das microrregiões

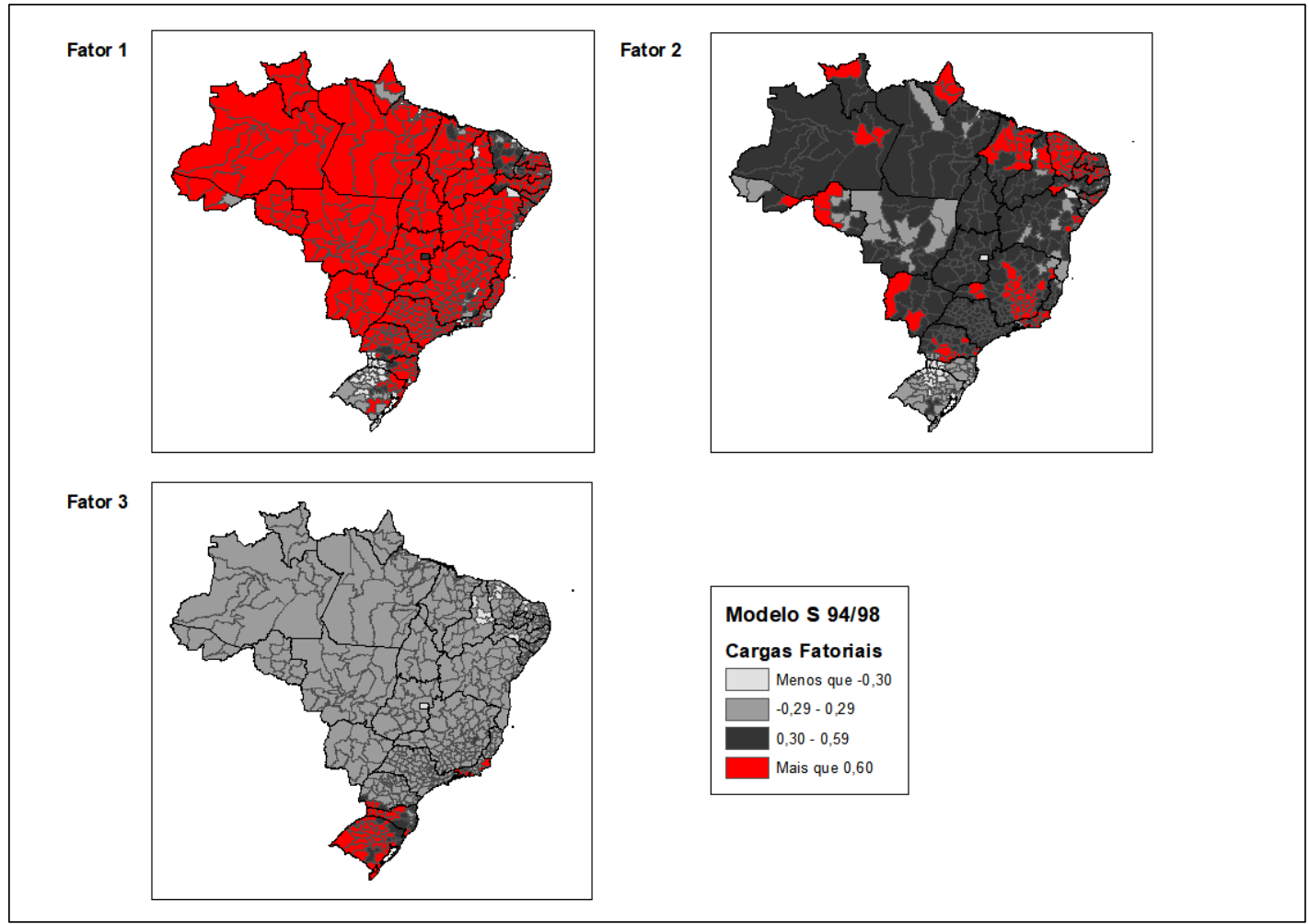

Fonte: Elaborada pelos autores com base em dados do TSE e do IBGE. 
Tabela 5

Média da porcentagem de votos para as microrregiões agrupadas em cada fator extraído na análise fatorial do modelo $S$ para $o$ período 1994-1998 com cargas fatoriais maiores que 0,6

\begin{tabular}{|l|c|c|c|c|c|c|}
\hline & \multicolumn{2}{|c|}{ Fator 1 } & \multicolumn{2}{c|}{ Fator 2 } & \multicolumn{2}{c|}{ Fator 3 } \\
\hline Eleições & PT & Forças antipetistas & PT & Forças antipetistas & PT & Forças antipetistas \\
\hline 1994 & 20,54 & 64,09 & 21,42 & 65,17 & 30,92 & 29,60 \\
\hline 1998 & 22,33 & 62,91 & 28,29 & 48,57 & 47,11 & 40,15 \\
\hline
\end{tabular}

Fonte: Elaborada pelos autores com base em dados do TSE e do IBGE.

A análise fatorial do modelo S referente ao período 2006-2018, utilizando o método de rotação do tipo ortogonal Varimax, resulta na extração de sete fatores "naturais" representando 100\% da variabilidade dos dados (Anexo 5); mas, após análise gráfica da curva da variância de cada valor no scree plot (Anexo 6), como sugerido por Figueiredo Filho e Silva Junior (2010), utilizamos apenas os três primeiros fatores que, juntos, representam $94 \%$ da variabilidade dos dados (Figura 2). Observando a média da porcentagem de votos das microrregiões com cargas fatoriais maiores que 0,6 para cada fator (Tabela 6), podemos argumentar que o fator 1 refere-se ao amplo agrupamento de microrregiões onde o PT obteve forte apoio eleitoral durante essas quatro eleições consecutivas, particularmente nas regiões Norte e Nordeste, e o norte do estado de Minas Gerais; o fator 2 refere-se às regiões onde, durante esse período, a maioria dos seus eleitores votou a favor das forças antipetistas (PSDB e PSL): região Sul, parte da região Centro-Oeste, estado de São Paulo e região sul do estado de Minas Gerais; finalmente, o fator 3, observando os dados da Tabela 6 , refere-se às regiões onde a maioria gradualmente mudou o seu voto do PT para as forças antipetistas, mais acentuadamente na eleição de 2018 no estado do presidente eleito Jair Bolsonaro, Rio de Janeiro. 
Figura 2

Representação gráfica das cargas fatoriais extraídas da análise fatorial do modelo $S$ referente aos resultados eleitorais dos dois primeiros colocados nas eleições presidenciais em primeiro turno de 2006 a 2018 na escala das microrregiões

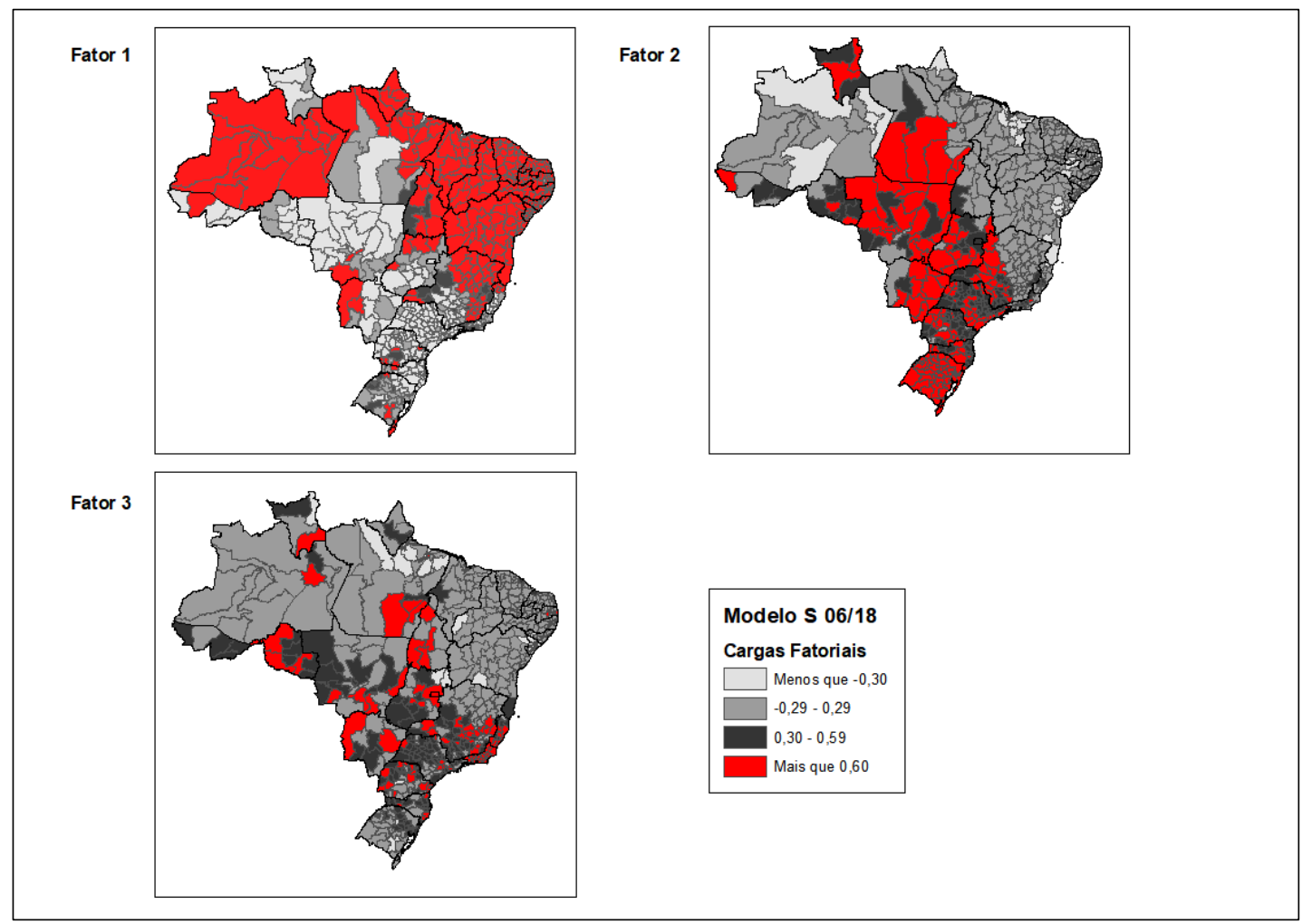

Fonte: Elaborada pelos autores com base em dados do TSE e do IBGE.

Tabela 6

Média da porcentagem de votos para as microrregiões agrupadas em cada fator extraído na análise fatorial do modelo $S$ para $o$ período 2006-2018 com cargas fatoriais maiores que 0,6

\begin{tabular}{|l|c|c|c|c|c|c|}
\hline & \multicolumn{2}{|c|}{ Fator 1 } & \multicolumn{2}{c|}{ Fator 2 } & \multicolumn{2}{c|}{ Fator 3 } \\
\hline Eleições & PT & Forças antipetistas & PT & Forças antipetistas & PT & Forças antipetistas \\
\hline 2006 & 65,39 & 29,57 & 35,4 & 57,92 & 47,95 & 42,24 \\
\hline 2010 & 64,97 & 23,87 & 43,97 & 43,95 & 42,97 & 35,35 \\
\hline 2014 & 65,1 & 18,66 & 39,56 & 45,15 & 37,43 & 37,87 \\
\hline 2018 & 54,26 & 24,79 & 24,55 & 53,49 & 22,37 & 55,69 \\
\hline
\end{tabular}

Fonte: Elaborada pelos autores com base em dados do TSE e do IBGE. 


\section{Classificando as eleições presidenciais}

Eleição de 1989: desviante

Os candidatos Ulysses Guimarães (PMDB) e Aureliano Chaves (PFL) pertenciam a partidos que formavam a base de sustentação do governo Sarney. Assim, o candidato vitorioso, Fernando Collor (PRN), mesmo que em certo momento daquela eleição (principalmente no segundo turno) tenha se tornado o preferido da grande mídia e dos setores conservadores da sociedade, não pode ser classificado como candidato "governista" e muito menos o seu governo pode ser considerado de continuidade ao governo anterior. A agenda política do governo Collor, ao contrário da do governo Sarney, caracterizou-se por um reformismo liberal (Sallum Jr., 2011), com privatizações, reformas administrativas, liberalização da economia e, mesmo que guarde semelhanças com a agenda do governo seguinte, o fato histórico é que os planos econômicos do governo foram um fracasso (Plano Collor 1 e 2) e Collor caiu após denúncias de corrupção. Por esses motivos (o partido majoritário não venceu a eleição e a agenda política foi diferente da anterior) a eleição de 1989 é classificada como "desviante". Acrescente-se que, pelo fato de esta ter sido a primeira eleição após a redemocratização, não cabe analisar a variável "padrão de votação" para essa classificação.

Eleições de 1994 e 1998: período de voto normal, eleições mantidas

A análise fatorial mostra que esse período específico foi de estabilidade nos padrões espaciais de votação tanto para as forças antipetistas (PSDB) quanto para o PT, mesmo que as altas cargas fatoriais sejam menos lineares do que no período de 2006 2018. Em relação à eleição de 1994, o candidato eleito, Fernando Henrique Cardoso (PSDB), era claramente o incumbente: após o impeachment de Collor, foi ministro da Fazenda do governo Itamar (PMDB) e, com o sucesso do Plano Real, foi lançado como candidato com o apoio deste último e reeleito em 1998. Como a literatura da época relata (Carreirão, 2002), a agenda política desses dois governos foi centrada na economia e no controle da inflação, deixando de lado os temas do desemprego e da desigualdade social, que se tornariam importantes na eleição de 2002. A economia teria sido a causa de curto prazo, e o tema de interesse que mobilizou os eleitores nas eleições de 1994 e 1998 teria sido os atributos pessoais do presidente para enfrentar as crises econômicas internacionais daquele período (crise financeira asiática em 1997 e russa em 1998). Dessa forma, se considerarmos a estabilidade nos padrões de votação, o continuísmo do governo FHC em relação ao período Itamar e a agenda política focada na economia, classificamos os pleitos de 1994 e 1998 como eleições mantidas e esse período, como de voto normal. 
Eleições de 2002 e 2006: período de realinhamento secular (desviante + convertida)

Na eleição de 2002, o candidato governista, José Serra (PSDB), perde para Luiz Inácio Lula da Silva no segundo turno, ou seja, o partido majoritário perde as eleições. No entanto, a análise fatorial do modelo T para o PT mostra que o padrão espacial do partido, em 2002, guarda semelhanças com 1994 e 1998, indicando, portanto, uma estabilidade. Essas duas características somadas, mudança do partido majoritário e manutenção nos padrões de votação, nos dão elementos para considerar essa eleição como desviante.

Durante o primeiro governo Lula, há uma mudança na agenda política, que passa de uma ênfase exacerbada na estabilidade da economia e no controle da inflação para uma outra voltada a combater a desigualdade social. É nesse quadro de mudança de agenda política e avaliação das medidas concretas do governo que a eleição seguinte ocorre (2006). Nela, o PT ganha novamente, mas agora ocorre uma mudança nos padrões de votação, como a análise fatorial do modelo $T$ mostra, tanto para o partido quanto para as forças antipetistas. De acordo com a classificação de Pomper (1967), a manutenção do partido majoritário e uma mudança dos padrões de votação nos dão argumentos para classificar essa eleição como convertida.

Essa mudança geográfica nos padrões de votação do PT em 2006 está bem documentada pela literatura (Hunter e Power, 2007; Nicolau e Peixoto, 2007; Soares e Terron, 2008). A partir de 2006, o PT passa a ser apoiado pelos eleitores de um extenso agrupamento regional de municípios menos populosos e mais pobres, concentrados, em sua maioria, na região Nordeste (Soares e Terron, 2008), apesar de manter em parte o seu apoio na periferia das áreas metropolitanas mais populosas das regiões Sul e Sudeste ${ }^{14}$. Esse padrão de alta concentração de votos para o PT nas regiões mais pobres do país estaria relacionado às políticas sociais promovidas pelo governo Lula durante o seu primeiro mandato. Alguns estudos (Bohl, 2011; Simoni Jr., 2017) relativizam a importância dos programas sociais para esse padrão de votação, mais especificamente o Bolsa Família, argumentando, por exemplo, que, historicamente, candidatos incumbentes sempre têm maior votação nas áreas menos desenvolvidas do país (Zucco, 2008), o chamado "qualunquismo" (Melo, 2014). Por outro lado, a perda de apoio entre a classe média e os mais escolarizados das grandes cidades e regiões mais desenvolvidas do país seria consequência das seguidas denúncias de casos de corrupção, desde o primeiro governo petista, com o chamado "Mensalão" (Hunter e Power, 2007).

A literatura sobre a teoria do realinhamento mostra que esse seria um fenômeno raro e que geralmente se manifesta na sua forma gradual (realinhamento secular): após uma primeira eleição pautada por um assunto de interesse que mobiliza os eleitores de uma forma mais intensa do que o usual, as linhas de apoio de voto normal anteriormente

14 Simoni Jr. (2017), por exemplo, mostra que na região Sul do país, no nível agregado de seções eleitorais, o partido, em 2002, já era o mais votado entre os "menos educados" (p. 103). 
estabelecidas são cruzadas e há uma alteração do partido hegemônico no poder. Em uma segunda eleição, em consequência das medidas concretas realizadas pelo novo governo, este é reeleito, mas acontece um rearranjo nos padrões de votação em torno de uma nova e dominante clivagem eleitoral que, ao longo do tempo, se demonstra duradouro.

Os dados apresentados neste artigo nos dão argumentos para classificarmos esse período 2002-2006 como de realinhamento secular ou gradual. Em 2002, há a formação de uma nova maioria com a troca do partido hegemônico no poder sem que ocorra uma mudança drástica nos padrões de votação. Quatro anos mais tarde, na reeleição do expresidente Lula, mudam os padrões de votação com o surgimento de uma clivagem eleitoral norte-sul, e esse novo padrão se mantém nas três eleições subsequentes (2010, 2014 e 2018). Essa constatação não é nova e foi levantada primeiro por Singer (2010) ao comparar as duas eleições do ex-presidente Lula (2002-2006) às de Franklin Roosevelt (1932-1936) na América:

Nesse caso, as eleições brasileiras de 2002 e 2006 poderão ser vistas, no futuro, como o início de um longo ciclo político, semelhante ao que aconteceu com as vitórias de Roosevelt em 1932 e 1936. Na primeira eleição (1932, 2002), formou-se uma nova maioria. Na segunda (1936, 2006), em uma votação de continuidade, a coalizão majoritária se manteve, mas com uma troca de posição importante no apoio ao presidente. Em ambos os casos (Roosevelt, Lula), a troca de apoio decorreu da política levada a cabo no primeiro mandato: a classe média se afastou do presidente, mas eleitores pobres tomaram o seu lugar.

O principal argumento contrário a essa ideia de um processo de realinhamento durante esse período 2002-2006 é o de que não havia, até 2006, um padrão claro de votação do PT, tanto geográfico (Terron e Soares, 2010) quanto social (Bohn, 2011; Limongi e Guarnieri, 2014). O partido, ao longo das eleições de 1994 e 1998, teria paulatinamente conquistado maior apoio eleitoral, chegando ao padrão de votação encontrado em 2002: bem votado em todas as regiões (Tabela 7) e em todas as camadas sociais, mas mantendo o padrão ou tendência de ser mais votado entre os eleitores com maior renda e escolaridade. Esse crescimento gradual de apoio, tanto territorial quanto social, explicaria por que, na nossa análise fatorial do modelo $\mathrm{T}$, as cargas fatoriais mais altas para o PT no período de 1989 a 2002 são menos lineares e ligeiramente mais baixas do que as de 2006 a 2018, indicando que os padrões de votação nessas primeiras eleições são menos semelhantes entre si do que nas do segundo período.

Embora não possamos afirmar que havia um alinhamento nos padrões de votação até 2006, a análise fatorial do modelo T mostra que, a partir dessa eleição, há uma linearidade dos valores de alta carga fatorial do fator 1 para ambos os grupos, PT e forças antipetistas (Tabelas 3 e 4), indicando, portanto, que a partir desse momento 
estabeleceu-se um alinhamento pelo menos parcial do voto, ou seja, o período 20022006 foi de fato determinante para a formação da clivagem eleitoral que se manteve nas outras três eleições seguintes.

Um outro aspecto sobre a teoria do realinhamento é a questão do assunto de interesse ou de crise geradora desse processo. Como vimos, três grandes temas foram indutores de processos de realinhamento na história estadunidense: escravidão, conflitos seccionais e a grande depressão. No caso brasileiro, estudos que analisaram o comportamento eleitoral na eleição de 2006 citam como fatores importantes para o voto: o desempenho econômico do governo e os sentimentos dos eleitores em relação ao PT (Rennó, 2007; Carreirão, 2007). Estudos posteriores, os quais analisam retrospectivamente essa eleição e as seguintes, apontaram esse último fator, sentimento dos eleitores sobre o PT (petismo-antipetismo) (Ribeiro, Carreirão e Borba, 2011, 2016; Samuels e Zucco, 2018), como o principal indutor do comportamento eleitoral durante esse período. Considerando que os governos do PT, através dos ganhos econômicos e programas sociais, tenham realmente alterado o patamar de vida das pessoas mais pobres do Brasil, principalmente nas regiões Norte e Nordeste, talvez essas populações sejam gratas durante a sua vida inteira, ocasionando como consequência uma era de congelamento do comportamento eleitoral (Mayhew, 2002). Por outro lado, devido aos seguidos casos de corrupção (Mensalão e Lava Jato) e a partir da crise econômica surgida no segundo governo Dilma (2015), o antipetismo se manifestou com mais força principalmente entre as classes média e alta do país, que, demograficamente, se concentram nas regiões mais desenvolvidas. Podemos supor que o próprio petismoantipetismo, mais do que uma clivagem social pobre-rico, seja, no caso brasileiro, o que mantém os padrões de votação "normais" durante esse período (2006-2018).

Tabela 7

Porcentagem de votos por região para o PT no primeiro turno das eleições de 1989 a 2018

\begin{tabular}{|l|c|c|c|c|c|c|c|c|}
\hline Regiões & $\mathbf{1 9 8 9}$ & $\mathbf{1 9 9 4}$ & $\mathbf{1 9 9 8}$ & $\mathbf{2 0 0 2}$ & $\mathbf{2 0 0 6}$ & $\mathbf{2 0 1 0}$ & $\mathbf{2 0 1 4}$ & $\mathbf{2 0 1 8}$ \\
\hline Norte & 18,7 & 25,52 & 26,52 & 44,41 & 56,06 & 49,23 & 50,05 & 36,8 \\
\hline Nordeste & $\mathbf{2 1 , 6 7}$ & $\mathbf{3 0 , 3}$ & 31,64 & 45,88 & $\mathbf{6 6 , 7 7}$ & $\mathbf{6 1 , 6 3}$ & $\mathbf{5 9 , 6 8}$ & $\mathbf{5 0 , 6}$ \\
\hline Sudeste & 16,93 & 25,58 & 31,19 & 46,47 & 43,27 & 40,88 & 32,39 & 19,19 \\
\hline Sul & 7,71 & 28,14 & $\mathbf{3 8 , 7 6}$ & $\mathbf{4 9 , 4 5}$ & 34,87 & 42,1 & 36,32 & 19,81 \\
\hline Centro-Oeste & 15,26 & 24,82 & 22,06 & 43,07 & 38,48 & 39,89 & 32,69 & 20,78 \\
\hline
\end{tabular}

Fonte: Elaborada pelos autores com base em dados do TSE, Ipeadata e Cepesp Data. Nota: Em destaque, região com maior número de votos para o PT em porcentagem em cada eleição. 
Eleições de 2010 e 2014: eleições mantidas

Assim como as eleições de 1994 e 1998, classificamos as eleições de 2010 e 2014 como mantidas, pois o partido majoritário, o PT, se mantém no poder, e a análise fatorial do modelo $T$ mostra que esse período é de estabilidade, tanto para o partido quanto para as forças antipetistas, repetindo aquele padrão de votação formado na eleição de 2006 como bem a literatura da época documenta (Marzagão, 2013; Magalhães, Silva e Dias, 2015). Também classificamos esse período como de voto normal ao observar que, apesar das variações, de maneira geral, as linhas básicas de apoio eleitoral não se alteram, como pode ser observado na Tabela 6, principalmente quando observamos os fatores 1 e 2 referentes à análise fatorial do modelo $\mathrm{S}$.

Eleição de 2018: eleição desviante

Com a contestação dos resultados da eleição de 2014 pelo candidato perdedor, Aécio Neves, do PSDB, e a subsequente crise política e econômica, os acontecimentos levaram ao impeachment da ex-presidente Dilma Roussef, do PT, em agosto de 2016, assumindo, tal como em 1993, um vice do PMDB ${ }^{15}$, Michel Temer.

Apesar da baixa popularidade e das denúncias envolvendo a cúpula do governo, Temer adotou uma agenda política reformista liberal que, na prática, foi bem-sucedida: aprovaram-se no Congresso Nacional a PEC dos gastos públicos (241/55) e a reforma trabalhista. Mesmo assim, a eleição de 2018 teve contornos parecidos com a de 1989, pois a maioria dos candidatos ${ }^{16}$ buscou se dissociar desse governo impopular. Dessa forma, assim como Collor, o candidato eleito, Bolsonaro, não representou a continuidade, embora o seu governo tenha dado continuidade à agenda liberal de reformas iniciada por Temer.

A análise fatorial do modelo T (Tabelas 3 e 4) indica que, de uma maneira geral, houve manutenção do padrão espacial de votação, tanto para o PT quanto para as forças antipetistas em relação às eleições anteriores, embora o padrão de votação de Bolsonaro seja ligeiramente diferente do das eleições anteriores do PSDB (2006, 2010 e 2014).

Usando a classificação de Campbell (1966), fundamentada no conceito de voto normal, apesar de aqui estarmos analisando dados agregados, a eleição de 2018 pode ser considerada "desviante" devido a causas de curto prazo fortes (crise econômica, política, impeachment da ex-presidente Dilma, prisão do ex-presidente Lula e atentado contra o então candidato Bolsonaro). Nessa eleição, houve uma flutuação acentuada dos apoios eleitorais a favor do partido minoritário (forças antipetistas), fazendo com que Bolsonaro ganhasse as eleições, embora respeitando as linhas de apoio de voto normal estabelecidas no passado.

\footnotetext{
15 Em dezembro de 2017 o partido mudou o nome da legenda para MDB.

${ }^{16}$ Com exceção do candidato Henrique Meirelles, do MDB.
} 
Períodos de desestabilização causados por crises econômicas e políticas, de acordo com a literatura sobre o desalinhamento eleitoral (Dalton, McAllister e Wattenberg, 2003; Carreras, Morgenstern e Su, 2013; Inglehart e Norris, 2016), historicamente fazem com que partidos e candidatos populistas, "anti-establishment" e "outsiders" tenham maior chance eleitoral, enquanto os partidos mais tradicionais perdem espaço. Esse seria o caso do candidato de extrema-direita, Bolsonaro, substituindo o PSDB na preferência do eleitorado antipetista. Cabe ressaltar que, diferentemente de países europeus, como Alemanha, Áustria ou Grécia, onde partidos de extrema-direita "anti-establishment" conquistaram uma relativa base eleitoral, o apoio ao candidato Bolsonaro, em 2018, apresenta mais um caráter personalista, o chamado "bolsonarismo", do que necessariamente um apoio ao seu partido, o PSL ${ }^{17}$.

Como vimos, a classificação de uma eleição ou de um período como críticos (realinhamento) necessariamente ocorre a posteriori, porque precisamos saber as consequências da eleição em questão e das ações do novo governo para o comportamento eleitoral, como foi o caso da primeira eleição do ex-presidente Lula, em 2002, e do seu primeiro governo. A mesma situação se apresenta agora em relação ao governo Bolsonaro. Podemos especular que as ações do primeiro mandato do presidente Bolsonaro deverão ser determinantes para sabermos como esse período iniciado em 2019 será lembrado: (1) como uma mera eleição desviante dentro de um período de voto normal mais amplo, caso na próxima eleição a estabilidade dos padrões de votação formados em 2006 se mantenha, ou (2) uma eleição desviante que, junto com as ações do novo governo, criará uma nova clivagem dentro do eleitorado, modificando os padrões de votação estabelecidos anteriormente em um novo processo de realinhamento.

Para a primeira hipótese, não há necessidade de haver uma alternância de poder, no caso, a volta do PT, mas, simplesmente, a manutenção das linhas de apoio "normais", iniciadas em 2006, oscilando entre os dois grandes grupos. Em relação à segunda hipótese, talvez o resultado da eleição de 2022 traga subsídios para, por exemplo, referendarmos ou não a tese do "qualunquismo" (Melo, 2014), caso os eleitores das regiões menos desenvolvidas do país se "alinhem" ao candidato governista, modificando os atuais padrões de voto normal.

O Quadro 2 sintetiza o conjunto de variáveis e argumentos levados em consideração na classificação das eleições presidenciais brasileiras de 1989 a 2018 proposta por este artigo:

\footnotetext{
17 Em novembro de 2019, o presidente Jair Bolsonaro anunciou a sua desfiliação do PSL e a criação de um novo partido, o "Aliança pelo Brasil", que tem como sua maior liderança o próprio Bolsonaro, reforçando o caráter personalista do seu movimento político.
} 
Quadro 2

Resumo das informações e variáveis utilizadas como subsídio para a classificação das eleições presidenciais (1989-2018)

\begin{tabular}{|c|c|c|c|c|c|c|c|c|c|}
\hline \multirow[b]{2}{*}{ Ano } & \multicolumn{4}{|c|}{ Informações relevantes } & \multicolumn{3}{|c|}{ Variáveis } & \multicolumn{2}{|c|}{ Resultado } \\
\hline & Eleição & Governo* & Vitorioso & Grupo & $\begin{array}{c}\text { Partido } \\
\text { majoritário }\end{array}$ & $\begin{array}{c}\text { Padrão de } \\
\text { votação }\end{array}$ & $\begin{array}{l}\text { Agenda } \\
\text { política }\end{array}$ & Classificação & Período \\
\hline 1989 & 1989 & Sarney (PMDB) & Collor & Anti-PT & PMDB & - & $\begin{array}{c}\text { Reformismo } \\
\text { liberal }\end{array}$ & Desviante & - \\
\hline 1993 & - & Itamar (PMDB) & - & - & - & - & $\begin{array}{c}\text { Plano } \\
\text { Real }\end{array}$ & - & - \\
\hline 1994 & 1994 & Itamar (PMDB) & $\mathrm{FHC}$ & Anti-PT & PSDB** & Estabilidade & $\begin{array}{l}\text { Plano } \\
\text { Real }\end{array}$ & Mantida & Voto normal \\
\hline 1998 & 1998 & $\mathrm{FHC}(\mathrm{PSDB})$ & $\mathrm{FHC}$ & Anti-PT & PSDB & Estabilidade & $\begin{array}{c}\text { Plano } \\
\text { Real } \\
\end{array}$ & Mantida & Voto normal \\
\hline 2002 & 2002 & $\mathrm{FHC}(\mathrm{PSDB})$ & Lula & PT & PSDB & Estabilidade & $\begin{array}{l}\text { Políticas } \\
\text { sociais }\end{array}$ & Desviante & $\begin{array}{c}\text { Realinhamento } \\
\text { secular }\end{array}$ \\
\hline 2006 & 2006 & Lula (PT) & Lula & PT & PT & Mudança & $\begin{array}{l}\text { Políticas } \\
\text { sociais }\end{array}$ & $\begin{array}{c}\text { Convertida } \\
\text { (Crítica) }\end{array}$ & $\begin{array}{c}\text { Realinhamento } \\
\text { secular }\end{array}$ \\
\hline 2010 & 2010 & Lula (PT) & Dilma & PT & PT & Estabilidade & $\begin{array}{l}\text { Políticas } \\
\text { sociais }\end{array}$ & Mantida & Voto normal \\
\hline 2014 & 2014 & Dilma (PT) & Dilma & PT & PT & Estabilidade & $\begin{array}{l}\text { Políticas } \\
\text { sociais }\end{array}$ & Mantida & Voto normal \\
\hline 2016 & - & Temer (PMDB) & - & - & - & - & $\begin{array}{c}\text { Reformismo } \\
\text { liberal }\end{array}$ & - & - \\
\hline 2018 & 2018 & Temer (MDB) & Bolsonaro & Anti-PT & MDB & Estabilidade & $\begin{array}{c}\text { Reformismo } \\
\text { liberal }\end{array}$ & Desviante & Voto normal \\
\hline
\end{tabular}

Fonte: Elaborado pelos autores.

* No momento da eleição.

** Apoiado pelo presidente Itamar (PMDB).

\section{Conclusões}

Admitimos a dificuldade de encontrar uma classificação para as eleições presidenciais fundamentada na literatura internacional sobre eleições críticas em um contexto de disputa multipartidária, como é o caso do Brasil; porém, usando como parâmetros principais a classificação de Pomper (1967) e a interpretação para os resultados de análise fatorial sugerida por Archer e Taylor (apud Johnston et al. 2017) aplicada para os votos em porcentagem dos primeiros colocados das eleições presidenciais de 1989 a 2018, a verificação da hipótese deste artigo revelou a possibilidade de chegar a uma classificação por meio das variáveis utilizadas.

Outra constatação primordial deste estudo é que o eleitorado brasileiro está cada vez mais atento às ações programáticas dos governantes eleitos. Como vimos, para a classificação de uma eleição ou de um período como críticos (realinhamento), tornou-se muito relevante a incorporação dos padrões de continuidade ou de mudança da agenda política dos governos analisados no período de 1989 a 2018 e a aprovação ou não desta pelo eleitorado. 
A nossa classificação sugere a existência de três eleições consideradas desviantes (1989, 2002 e 2018), quatro eleições mantidas (1994, 1998, 2010 e 2014) e uma eleição crítica classificada como convertida (2006). Mais ainda, sugerimos a existência de um período de mudança (realinhamento secular) entre 2002 e 2006 e dois períodos de voto normal: um durante os governos FHC (1994-1998) e outro que começa a partir do padrão de votação formado na eleição de 2006 e que compreende as eleições de 2010, 2014 e 2018, sendo que esta última, devido à perda da hegemonia do PT, pelo menos inicialmente, é classificada neste artigo como desviante.

\section{Referências bibliográficas}

ARCHER, J. C.; TAYLOR, P. J. Section and party: a political geography of American presidential elections, from Andrew Jackson to Ronald Reagan. Chichester: Wiley, 1981.

BARTOLINI, S.; MAIR, P. Identity, competition and electoral availability: the stabilization of European electorates, 1885-1985. Cambridge: Cambridge University Press, 1990.

BLONDEL, J. The discipline of politics. London \& Boston: Butterworths, 1981.

Born, S. R. "Social policy and vote in Brazil: Bolsa Família and the shifts in Lula's electoral base". Latin American Research Review, vol. 46, no 1, p. 54-69, 2011.

CAmpbell, A. A classification of elections. In: CAmpBell, A., et al. (eds.). Elections and the political order. New York: Wiley, 1966.

Campbell, A., et al. The American voter. New York: Wiley, 1960.

CARAMANI, D. The dynamic perspective: state formation and mass democratization. In: CARAMANI, D. The nationalization of politics: Cambridge studies in comparative politics. Cambridge: Cambridge University Press, p. 195-250, 2004.

CARreirão, Y. S. "Identificação ideológica e voto para presidente". Opinião Pública, Campinas, vol. 8, n० 1 , p. 54-7, 2002.

"Identificação ideológica, partidos e voto na eleição presidencial de 2006". Opinião Pública, Campinas, vol. 13, no 2, p. 307-339, 2007.

Carreras, M.; Morgenstern, S.; Su, Y. "Refining the theory of partisan alignments: evidence from Latin America". Party Politics, vol. 21, no 5, p. 671-685, 2013.

Converse, P. E. The concept of a normal vote. In: CAmpBelL, A., et al. (eds.). Elections and the political order. New York: Wiley, 1966.

DALton, R. J.; MCAllister, I.; WATtenberg, M. P. The consequences of partisan dealignment. In: DALton, R. J.; WATtenberg, M. P. (eds.). Parties without partisans: political change in advanced industrial democracies. Oxford: Oxford University Press, p. 37-63, 2000.

"Democracia e identificação partidária nas sociedades industriais avançadas". Análise

Social, vol. 38, no 167, p. 295-320, 2003. 
DALTON, R. J.; SCOTT, C. F.; BECK, P. (eds.). Electoral change: realignment and dealigment in advanced industrial democracies. Princeton: Princeton University Press, 1984.

Figueiredo, A. C., et al. "Partidos e distribuição espacial dos votos na cidade de São Paulo (19942000)". Novos Estudos Cebrap, São Paulo, no 64, p. 153-176, 2002.

Figueiredo Filho, D. B.; Silva Junior, J. A. "Visão além do alcance: uma introdução à análise fatorial". Opinião Pública, Campinas, vol. 16, no 1, p. 160-185, 2010.

Gallagher, M.; LAVer, M.; Mair, P. Cleavage structures and electoral change. In: Gallagher, M.; LAVER, M.; MAIR, P. Representative government in modern Europe. New York: McGraw-Hill Higher Education, p. 278-325, 2011.

HUNTER, W.; POWER, T. Recompensando Lula: Poder Executivo, política social e as eleições brasileiras de 2006. In: Melo, C. R.; MANuel A. S. (orgs.). A democracia brasileira: balanço e perspectivas para o século 21. Belo Horizonte: Editora UFMG, 2007.

INGLEHART, R.; NORRIS, P. "Trump, Brexit, and the rise of populism: economic have-nots and cultural backlash". In: American Political Science Association Annual Meeting, Philadelphia, 2016.

JACOB, C. R., et al. "A eleição presidencial de 2006 no Brasil: continuidade política e mudança na geografia eleitoral". Revista Alceu, vol. 10, no 9, p. 232-261, 2009.

Johnston, R., et al. "Was the 2016 United States' presidential contest a deviating election? Continuity and change in the electoral map - or "Plus ça change, plus c'est la mème géographie". Journal of Elections, Public Opinion and Parties, vol. 27, no 4, p. 369-388, 2017.

KEY, V. O. "A theory of critical elections". The Journal of Politics, vol. 17, no 1, p. 3-8, 1955.

198-210, 1959.

"Secular realignment and the party system". The Journal of Politics, vol. 21, no 2, p.

KNUCKEY, J. "Classification of presidential elections: an update". Polity, vol. 31, no 4, p. 639-653, 1999.

LIMONGI, F.; GUARNIERI, F. "A base e os partidos: as eleições presidenciais no Brasil pósredemocratização". Novos Estudos - Cebrap, São Paulo, no 99, p. 5-24, 2014.

LIPSET, S. M.; RoKKAN, S. Cleavage structures, party systems, and voter alignments. In: MAIR, P. The West European party system. Oxford: Oxford University Press, 1990.

LöWy, M. "Conservadorismo e extrema-direita na Europa e no Brasil". Serviço Social e Sociedade, São Paulo, no 124, p. 652-664, 2015.

MAgAlhães, A. M.; Silva, M. E. A.; DiAS, F. M. "Eleição de Dilma ou segunda reeleição de Lula? Uma análise espacial do pleito de 2010". Opinião Pública, Campinas, vol. 21, no 3, p. 535-573, 2015.

MARZagão, T. "A dimensão geográfica das eleições brasileiras". Opinião Pública, Campinas, vol. 19, no 2, p. 270-290, 2013.

MAYHEW, D. R. Electoral realignments: a critique of an American genre. New Haven, CT: Yale University Press, 2002.

Melo, M. A. "Lulismo ou 'qualunquismo'"? Valor Econômico, 15 jan. 2014.

Disponível em: <https://qualidadedademocracia.com.br/lulismo-ou-qualunquismo-d8cea335e496>. Acesso em: out. 2019. 
PADRÕES DE VOTAÇÃO NO TEMPO E NO ESPAÇO: CLASSIFICANDO AS ELEIÇÕES PRESIDENCIAIS BRASILEIRAS

Nicolau, J.; Peixoto, V. As bases municipais da votação de Lula em 2006. In: Reis Velloso, J. P. (coord.). Quem elegeu Lula? Cadernos do Fórum Nacional, nº 19866, 2007.

Norris, P. "A tese da 'nova clivagem' e a base social do apoio à direita radical". Opinião Pública, vol. 11, no 1, p. 1-32, 2005.

PEDERSEN, M. N. "The dynamics of European party systems: changing patterns of electoral volatility". European Journal of Political Research, vol. 7, no 1, p. 1-26, 1979.

Pomper, G. "Classification of presidential elections". The Journal of Politics, vol. 29, no 3, p. 535-566, 1967.

RenNó, L. "Escândalos e voto: as eleições presidenciais brasileiras de 2006". Opinião Pública, vol. 13, no 2, p. 260-282, 2007.

Ribeiro, E.; CARREIRÃo, Y.; BorBA, J. "Sentimentos partidários e atitudes políticas entre os brasileiros". Opinião Pública, vol. 17, n² 2, p. 333-368, 2011.

"Sentimentos partidários e antipetismo: condicionantes e covariantes". Opinião Pública,

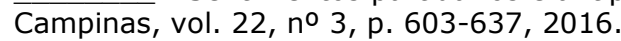

SALLUM JR., B. "Governo Collor: o reformismo liberal e a nova orientação da política externa brasileira". Dados - Revista de Ciências Sociais, Rio de Janeiro, vol. 54, nº 2, p. 259-288, 2011.

SAmuels, D. J.; Zucco, C. "The power of partisanship in Brazil: evidence from survey experiments". American Journal of Political Science, vol. 58, no 1 p. 212-225, 2014.

. Partisans, antipartisans, and nonpartisans: voting behavior in Brazil. Cambridge:

Cambridge University Press, 2018.

SCHATTSCHNEIDER, E. E. The semisovereign people: a realist's view of democracy in America. Boston: Wadsworth, 1975.

Shelley, F. M., et al. Political geography of the United States. New York: The Guilford Press, 1996.

SIMONI JR., S. "Política distributiva e competição presidencial no Brasil: Programa Bolsa-Familia e a tese do realinhamento eleitoral". Tese de Doutorado, Departamento de Ciência Política, USP, São Paulo, 2017.

Singer, A. "O lulismo e seu futuro". Revista Piauí, no 49, 2010. Disponível em:

<https://piaui.folha.uol.com.br/materia/o-lulismo-e-seu-futuro/>. Acesso em: nov. 2019.

SoARES, G. A. D.; TerRon, S. L. "Dois Lulas: a geografia eleitoral da reeleição (explorando conceitos, métodos e técnicas de análise geoespacial)". Opinião Pública, Campinas, vol. 14, no 2, p. 269-301, 2008.

SUNDQUIST, J. L. Dynamics of the party system, alignment and realignment of political parties in the United States. Revised Edition. Washington, DC: Brookings Institution, 1983.

Terron, S. L.; SoAres, G. A. D. "As bases eleitorais de Lula e do PT: do distanciamento ao divórcio". Opinião Pública, Campinas, vol. 16, no 2, p. 310-337, 2010.

Zucco, C. "The president's 'new' constituency: Lula and the pragmatic vote in Brazil's 2006 presidential elections". Journal of Latin American Studies, vol. 40, no 1, p. 29-49, 2008. 


\section{Anexos}

Anexo 1

Scree plot dos fatores gerados a partir da análise fatorial do modelo $\mathrm{T}$ para os resultados eleitorais do PT em primeiro turno nas eleições presidenciais de 1989 a 2018 na escala das microrregiões

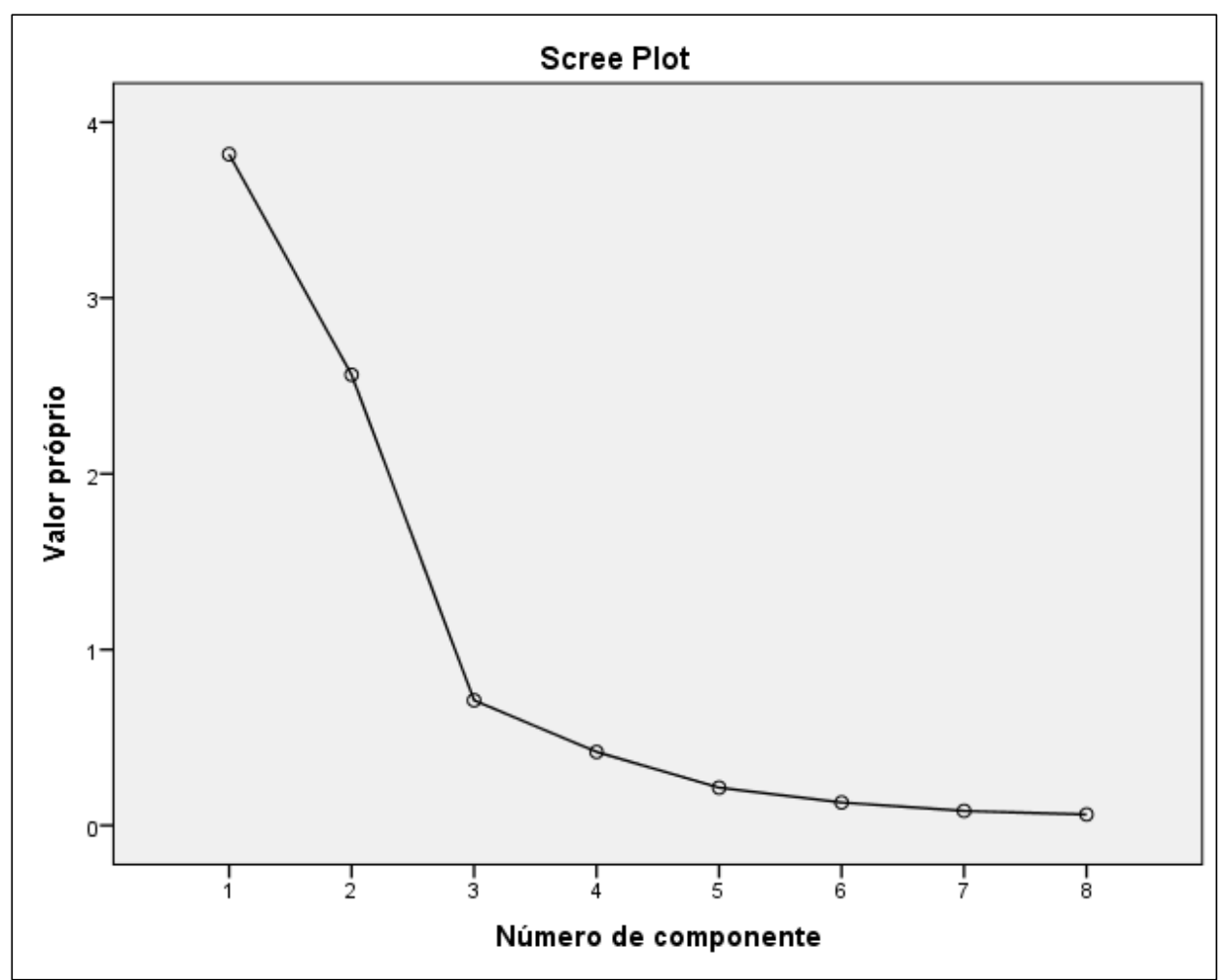

Fonte: Elaborado pelos autores com base em dados do TSE e do IBGE. 
Anexo 2

Scree plot dos fatores gerados a partir da análise fatorial do modelo $\mathbf{T}$ para os resultados eleitorais das forças antipetistas em primeiro turno nas eleições presidenciais de 1989 a 2018 na escala das microrregiões

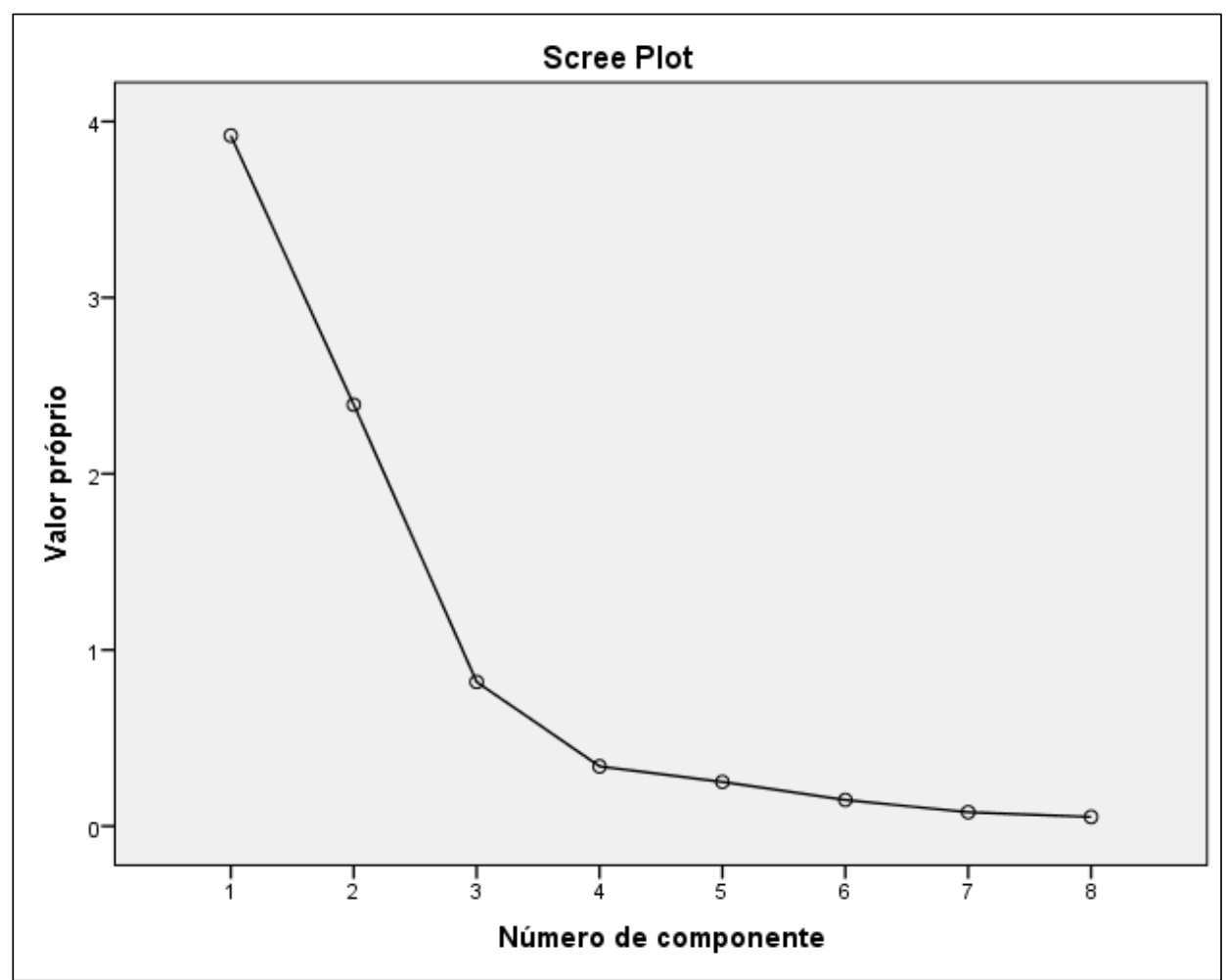

Fonte: Elaborado pelos autores com base em dados do TSE e do IBGE.

Anexo 3

\begin{tabular}{|c|c|c|c|c|c|c|}
\hline \multicolumn{7}{|c|}{ Variação total explicada } \\
\hline \multirow[t]{2}{*}{ Componente } & \multicolumn{3}{|c|}{ Valores próprios iniciais } & \multicolumn{3}{|c|}{$\begin{array}{c}\text { Somas de extração de carregamentos ao } \\
\text { quadrado }\end{array}$} \\
\hline & Total & \% variação & $\%$ cumulativa & Total & \% variação & \% cumulativa \\
\hline 1 & 476,824 & 85,452 & 85,452 & 476,824 & 85,452 & 85,452 \\
\hline 2 & 45,339 & 8,125 & 93,578 & 45,339 & 8,125 & 93,578 \\
\hline 3 & 35,837 & 6,422 & 100 & 35,837 & 6,422 & 100 \\
\hline
\end{tabular}

Fonte: Elaborado pelos autores com base em dados do TSE e do IBGE. 
Anexo 4

Scree plot dos fatores gerados a partir da análise fatorial do modelo $\mathbf{S}$ referente ao período 1994-1998

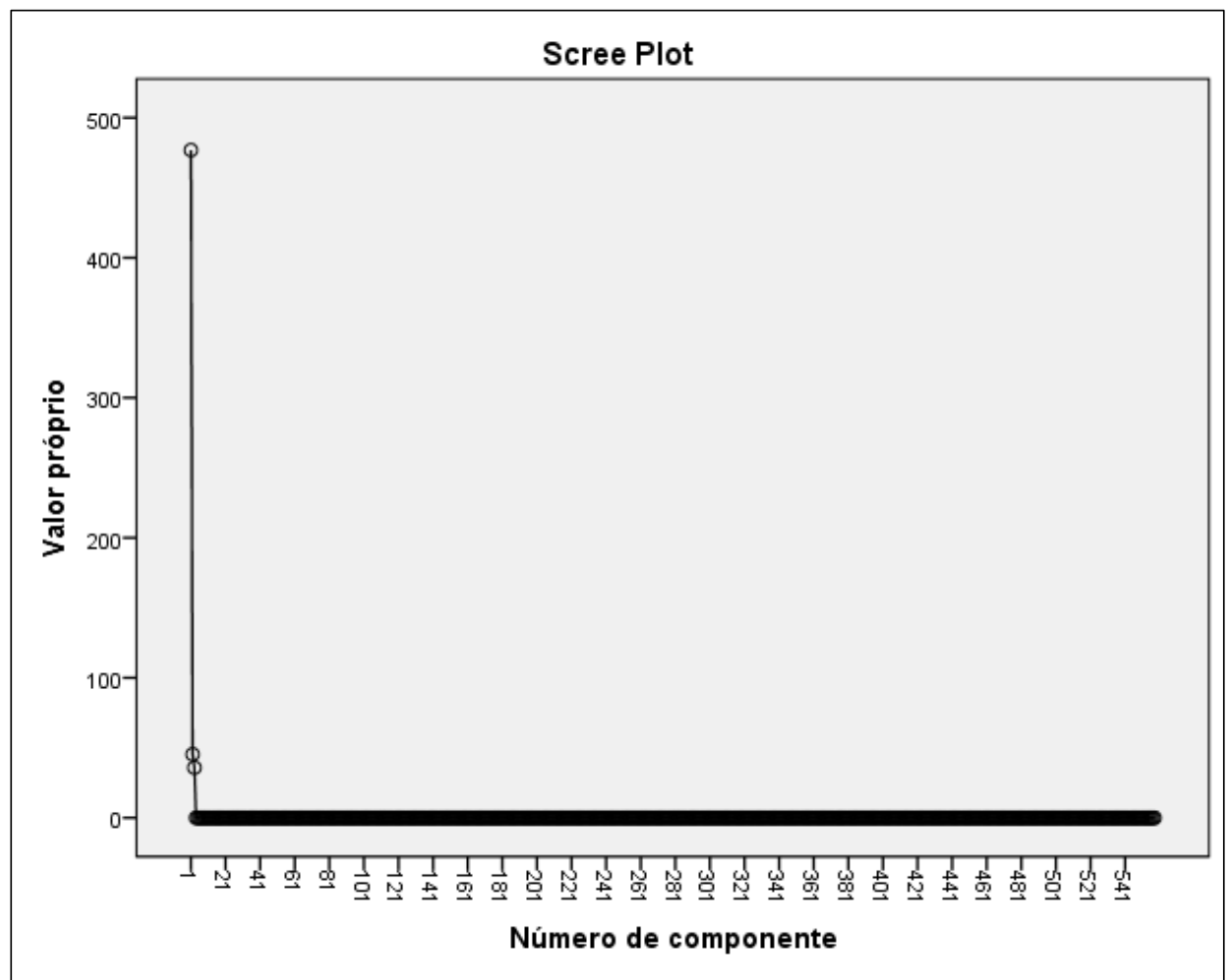

Fonte: Elaborado pelos autores com base em dados do TSE e do IBGE.

Anexo 5

\begin{tabular}{|l|c|c|c|c|c|c|}
\hline \multicolumn{7}{|c|}{ Variação total explicada } \\
\hline Componente & \multicolumn{7}{|c|}{ Valores próprios iniciais } & \multicolumn{2}{c|}{$\begin{array}{c}\text { Somas de extração de carregamentos } \\
\text { ao quadrado }\end{array}$} \\
\hline & Total & \% variação & \% cumulativa & Total & \% variação & \% cumulativa \\
\hline 1 & 360,21 & 64,5 & 64,5 & 360,21 & 64,5 & 64,5 \\
\hline 2 & 128,297 & 22,9 & 87,5 & 128,297 & 22,9 & 87,5 \\
\hline 3 & 39,211 & 7 & 94,5 & 39,211 & 7 & 94,5 \\
\hline 4 & 15,649 & 2,8 & 97,3 & & & \\
\hline 5 & 7,023 & 1,2 & 98,6 & & & \\
\hline 6 & 6,028 & 1 & 99,7 & & & \\
\hline 7 & 1,582 & 0,2 & 100 & & & \\
\hline
\end{tabular}

Fonte: Elaborado pelos autores com base em dados do TSE e do IBGE. 


\title{
Anexo 6
}

\section{Scree plot dos fatores gerados a partir da análise fatorial do modelo $S$ referente ao período 2006-2018}

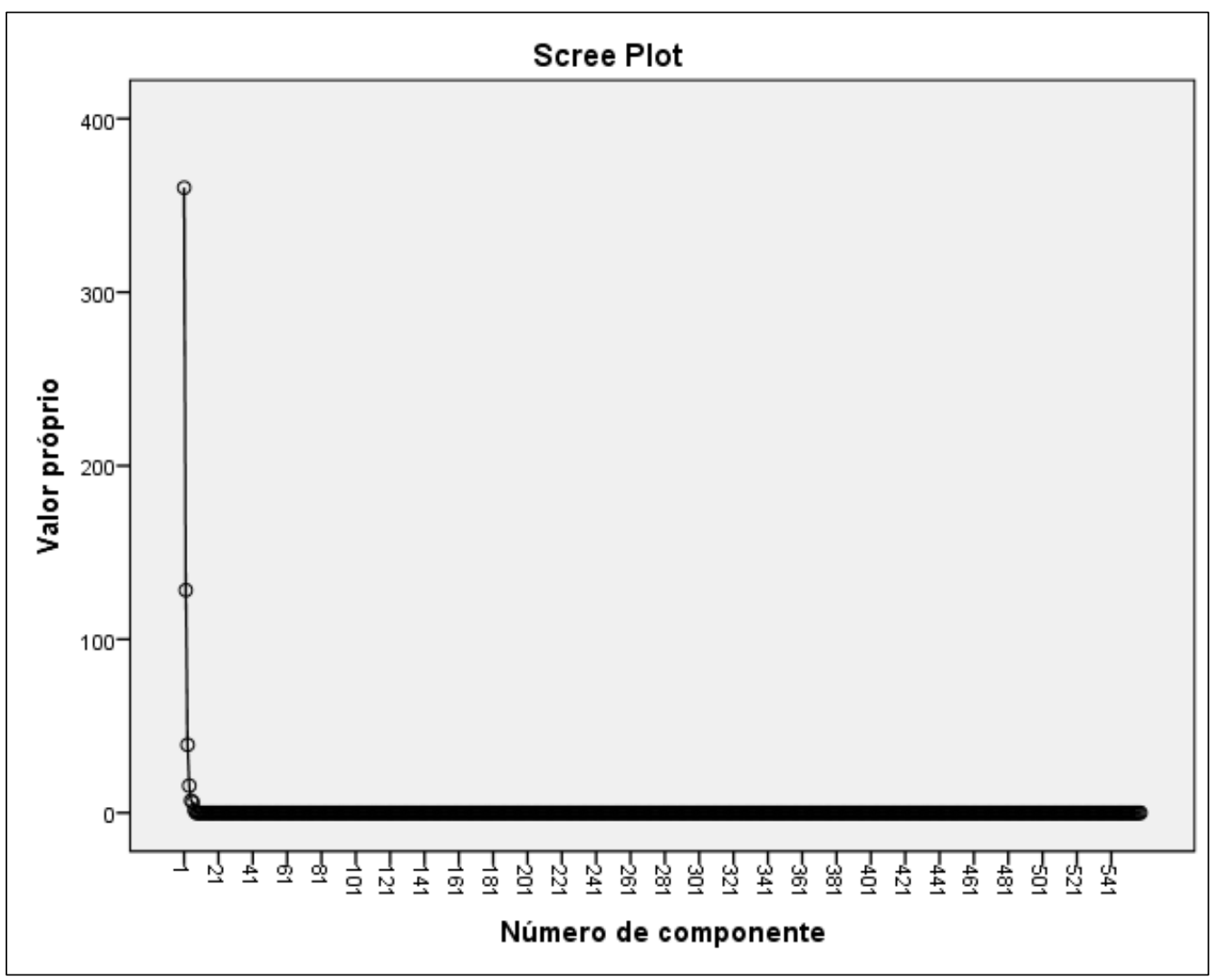

Fonte: Elaborado pelos autores com base em dados do TSE e do IBGE

\begin{abstract}
Voting patterns in time and space: classifying Brazilian presidential elections

In 2018, Brazil held its eighth post-redemocratization presidential election, accumulating empirical evidence that are crucial to the analysis of the characteristics of electoral processes that may be responsible for substantial changes in the distribution of power among political parties. From a conceptual basis grounded in international literature on critical elections, this article aims to create a classification for Brazilian elections. As the main subsidy for this classification, it is analyzed simultaneously, in time and space, through factor analysis, the electoral performance of the first runners in the presidential elections of 1989 to 2018 in the first round of the scale of the Brazilian micro regions seeking to identify the support regions and periods of stability and changing voting patterns. As a result, presidential elections are classified into three types: maintained, deviant and converted (critical).
\end{abstract}

Keywords: presidential elections; critical elections; realignment; electoral behavior; Brazil 


\section{Resumen}

Patrones de votación en el tiempo y el espacio: clasificación de las elecciones presidenciales brasileñas

En 2018, Brasil celebró su octava elección presidencial posterior a la redemocratización, acumulando evidencia empírica crucial para el análisis de las características de los procesos electorales que pueden ser responsables de cambios sustanciales en la distribución del poder entre los partidos políticos. Desde una base conceptual fundamentada en la literatura internacional sobre elecciones críticas, este artículo tiene como objetivo crear una clasificación para las elecciones brasileñas. Como principal subsidio para esta clasificación, se analiza simultáneamente, en el tiempo y en el espacio, a través del análisis factorial, el desempeño electoral de los primeros corredores en las elecciones presidenciales de 1989 a 2018 en la primera ronda de la escala de las micro regiones brasileñas que buscan identificar las regiones de apoyo y períodos de estabilidad y cambios en los patrones de votación. Como resultado, las elecciones presidenciales se clasifican en tres tipos: mantenidas, desviadas y convertidas (críticas).

Palabra claves: elecciones presidenciales; elecciones críticas; realineamiento; comportamiento electoral; Brasil

\section{Résumé}

Modèles de vote dans le temps et l'espace: classification des élections présidentielles brésiliennes

En 2018, le Brésil a tenu sa huitième élection présidentielle post-redémocratisation, accumulant des preuves empiriques cruciales pour l'analyse des caractéristiques des processus électoraux qui peuvent être responsables de changements substantiels dans la répartition du pouvoir entre les partis politiques. À partir d'une base conceptuelle fondée sur la littérature internationale sur les élections critiques, cet article vise à créer une classification pour les élections brésiliennes. Principale subvention de ce classement, elle analyse simultanément, dans le temps et l'espace, à travers l'analyse factorielle, les performances électorales des premiers coureurs aux élections présidentielles de 1989 à 2018 au premier tour de l'échelle des microrégions brésiliennes cherchant à identifier les régions d'appui. et des périodes de stabilité et de modification des modes de scrutin. En conséquence, les élections présidentielles sont classées en trois types: maintenues, déviantes et converties (critiques).

Mot-clés: élections présidentielles; élections critiques; réalignement; comportement électoral; Brésil

Artigo submetido à publicação em 15 de fevereiro de 2019. Artigo ressubmetido à publicação em 10 de novembro de 2019. Versão final aprovada em 7 de janeiro de 2020.

Opinião Pública adota a licença Creative Commons CC-BY. 